bioRxiv preprint doi: https://doi.org/10.1101/2021.09.13.460037; this version posted September 15, 2021. The copyright holder for this preprint (which was not certified by peer review) is the author/funder, who has granted bioRxiv a license to display the preprint in perpetuity. It is made available under aCC-BY 4.0 International license.

\title{
Morphometric Analysis of Lungfish Endocasts Elucidates Early Dipnoan Palaeoneurological Evolution
}

Alice M. Clement ${ }^{* 1}$, T. J. Challands ${ }^{2}$, Richard Cloutier ${ }^{3}$, Laurent Houle ${ }^{3}$, Per E. Ahlberg ${ }^{4}$, Shaun P. Collin ${ }^{5}$ \& John A. Long ${ }^{1}$

*alice.clement@flinders.edu.au

1, College of Science \& Engineering, Flinders University, Adelaide, Australia; 2, School of Geosciences, University of Edinburgh, Edinburgh, UK; 3, Department of Biology, University of Quebec, Rimouski, Canada; 4, Subdepartment of Evolution and Development, Department of Organismal Biology, Uppsala University, Uppsala, Sweden; 5, School of Life Sciences, La Trobe University, Victoria, Australia.

\section{ABSTRACT}

Lungfish (Dipnoi) are lobe-finned fish (Sarcopterygii) that have persisted for over 400 million years from the Devonian Period to present day. They are the extant sister group to tetrapods and thus have the ability to provide unique insight into the condition of the earliest tetrapods as well as their own evolutionary history. The evolution of their dermal skull and dentition is relatively well understood, but this is not the case for the central nervous system. While the brain itself has very poor preservation potential and is not currently known in any fossil lungfish, substantial indirect information about it and associated structures such as the inner ears can be obtained from the cranial endocast. However, before the recent development of X-ray tomography as a palaeontological tool, these endocasts could not be studied non-destructively, and few detailed studies were undertaken. Here we describe and illustrate the endocasts of six Palaeozoic lungfishes (lowadipterus halli, Gogodipterus paddyensis, Pillararhynchus longi, Griphognathus whitei, Orlovichthys limnatis, and Rhinodipterus ulrichi) from tomographic scans. We combine these with six previously described lungfish endocasts (4 fossil and 2 recent taxa), also based on tomographic studies, into a 12-taxon data set for multivariate morphometric analysis using 17 variables. We find that the olfactory region appears to be more highly plastic than the hindbrain, and undergoes significant elongation in several taxa. Further, while the semicircular canals covary as an integrated module, the utriculus and sacculus of the inner ear instead vary independently of each other. The functional and phylogenetic implications of our findings are discussed.

\section{KEY WORDS}

Dipnoi; palaeoneurology; endocast; Palaeozoic; tomography; BPCA; InDaPCA.

\section{INTRODUCTION}

The field of palaeoneurology was founded a century ago and is a long-established branch of inquiry into fossil vertebrates (Edinger 1921). However relatively little attention has been given to investigation into the evolution of the brain in fossil fishes, most likely due to the fact that the brain-braincase relationship is generally not as close as in "higher" vertebrates such as birds and mammals (Jerison 1973). In spite of this, advances in imaging technologies are transforming the palaeoneurological landscape, enabling more indepth investigations of structure-function relationships (Bruner et al. 2018; Walsh \& Knoll 2011), including in early vertebrates. 
There has been relatively little attention paid to examining brain evolution in early lungfishes (Dipnoi), despite the crania of a large number of fossils having been described since early in the $19^{\text {th }}$ Century (Sedgwick \& Murchison 1828), more than 100 fossil lungfish specimens described and renewed taxonomic interest in lungfishes as the extant sister group of the tetrapods. Lungfish represent a unique evolutionary lineage, which has persisted for over $\mathbf{4 0 0}$ million years. Their crania differ quite remarkably from other sarcopterygian fishes in having lost the intracranial joint, possession of an autostylic jaw suspension, unique dentition and differences in the number and arrangement of dermal skull bones (Schultze 1986).

Homologues of skull roofing bones across sarcopterygians were difficult to identify, leading to the adoption of an alternate (and unique) labelling scheme that continues to be used today (Forster-Cooper 1937), with additions and updates from (Ahlberg 1991; Cloutier 1997; Miles 1977). Furthermore, lungfish skulls have undergone considerable reduction in the degree of ossification and the fusion and/or loss of bone, leading to a near 10-fold reduction in the number of dermal skull bones present in extant Dipnoi compared to some Devonian forms (Criswell 2015).

Currently, only eight species of lungfishes have had the endocast (the negative space within the cranium) described or illustrated in any considerable manner (either full or partial), i.e. Dipnorhynchus sussmilchi (Campbell \& Barwick 1982; Clement et al. 2016a), Chirodipterus wildungensis (Säve-Söderbergh 1952), 'Chirodipterus' australis (Henderson \& Challands 2018; Miles 1977), Griphognathus whitei and Holodipterus gogoensis (Miles 1977), Dipnorhynchus kurikae (Campbell \& Barwick 2000), Rhinodipterus kimberleyensis (Clement \& Ahlberg 2014), and Dipterus valenciennesi (Challands 2015). Additional fragmentary neurocranial information is also known in Scaumenacia curta (Boirot et al. in press).

Some early investigations into fossil lungfish endocranial morphology led Stensiö (1963) to suggest that the dipnoan brain 'type' had developed by the beginning of the Devonian and has not undergone any significant changes since that time. However, recent work has shown that the endocasts of some Devonian lungfish continued to change in morphology with the acquisition of new characters certainly into the Upper Devonian period, while also retaining other primitive characteristics (Challands 2015; Clement \& Ahlberg 2014; Clement et al. 2016a).

The polarity of such characters in the cranial endocasts of fossil lungfish has largely been determined by reference to brains of extant taxa; the Lepidosireniformes (Protopterus and Lepidosiren) and the Ceratodontiformes (Neoceratodus). For example, Northcutt $(1986 ; 2011)$ considered pedunculate olfactory bulbs to be a primitive state in the Dipnoi as this characteristic is observed in Neoceratodus, considered the most morphologically conservative of the extant dipnoan taxa, and also in the extant coelacanth Latimeria (Dutel et al. 2019). Furthermore, pedunculate olfactory bulbs are also seen in stem osteichthyans (Clement et al. 2018), as well as several more basal outgroups such as placoderms (Zhu et al. 2021). Determining the polarity of endocast characters is important at this juncture in dipnoan palaeoneurological research as we are now in a position to recognise and apply more neurocranial characters to phylogenetic analyses. Following on from Friedman's detailed analysis of lungfish interrelationships based on neurocranial evidence (Friedman 2007), Clement et al. (2016a) conducted the first phylogenetic analysis of Palaeozoic lungfishes based entirely on endocast characters, emphasising their use for such studies.

Here, we investigate the endocranial morphology of six Devonian dipnoans (lowadipterus halli, Gogodipterus paddyensis, Pillararhynchus longi, Griphognathus whitei, Orlovichthys limnatis, and Rhinodipterus ulrichi) 
from synchrotron and computed tomography (CT), and compare them with those taxa already known using multivariate morphometric analyses (Figure 1). We hypothesise that, just as cranial elongation manifests in numerous ways by lengthening of either the snout, jaw or cheek regions, the neurocranium (and by consequence, the endocasts) of Devonian lungfishes will have also accommodated elongation by modifying different regions to varying extents.

\section{RESULTS}

\section{Description of Endocasts}

\section{Griphognathus whitei (NHMUK PV P56054).}

The skull and endocast of Griphognathus whitei show the extremity of the elongated morphotype; the endocast is more than four times longer than it is wide, measuring $130 \mathrm{~mm}$ in length but less than $30 \mathrm{~mm}$ in width (Supplementary Figure 1). However, it is the olfactory region and forebrain that have undergone significant elongation, with the mid and hind-brain of similar proportion to that in several other taxa (e.g. Rhinodipterus spp.). The shape of the nasal capsules is distinct from other lungfishes, in being particularly elongate and narrow oblong ovals. They are situated at the anterior end of remarkably long olfactory canals (comprising almost half the length of the entire endocast) that diverge from each other narrowly at $11^{\circ}$. Numerous canals that may contribute to a medial canal meshwork emanate from the dorsal surface of the olfactory tracts. The lateral branch of the canal for the ramus ophthalmicus profundus $n . V$ and the canal for the ramus buccalis $\mathrm{n}$.VII pass mediodorsally and lateral to the nasal capsule respectively whereas the lateral branch of the nasal vein enters the posterior wall of the nasal capsule.

The telencephalon is elongate with a distinct subpallium. A canal for the anterior cerebral vein is present dorsally on the telencephalon and is distinguished from a pineal eminence by it projecting laterally and curving ventrally. The hypophyseal recess is small and does not protrude far ventrally as in most other lungfishes. There are several small canals exiting the hypophyseal recess. To the anterior a single canal exits and then divides representing the canal for the palatine artery. The canal for the pituitary vein is small and exits antero-lateral and slightly dorsal to the canal for the palatine artery. Emanating from the posterolateral region of the hypophyseal recess the canals for the pseudobranchial arteries are present.

The mesencephalic region of the endocast is not well preserved and its dorsal margin is incomplete, although it appears to have been narrow and short. The rhombencephalic region appears relatively conserved and is similar in proportion to Rhinodipterus kimberleyensis (Clement \& Ahlberg 2014) of unremarkable length or width, and with space for housing the endolymphatic ducts in the supraoptic cavities dorsally. Unusually, the canals for the trigeminal complex (n.V) do not protrude far laterally in Griphognathus and are relatively difficult to discern.

Within the inner ear, the semicircular canals are thin and follow a less circular arc than in Chirodipterus and Gogodipterus, with the posterior and lateral canals being longer than the anterior canal. The lateral and anterior canals bear prominent swelling (for their ampullae) at their bases, while the ampulla in the posterior canal is less well defined. The sinus superior reaches the same level dorsally as the endolymphatic ducts above the roof of the cranial cavity. The utricular recess is relatively large and oblong when viewed laterally, while the sacculus is not as clearly defined as that in Rhinodipterus, and its pouches are separated widely from each other, thereby allowing space for a large notochord. 


\section{lowadipterus halli (FMNH PF 12323).}

Although the resolution of the scan data in lowadipterus halli does not allow for fine detail to be elucidated, overall morphology of the endocast and several other features can nevertheless be recognised (Supplementary Figure 2). The endocast ( $21 \mathrm{~mm}$ long, $7.5 \mathrm{~mm}$ wide) is high and narrow, and closely associated with the notochord ventrally. The telencephalic, diencephalic and mesencephalic regions are particularly narrow and high, with only a slight widening evident in the hindbrain region.

The nasal capsules are large and oval-shaped, connecting to the greater cranial cavity via their posteromedial corner. The olfactory canals are very short and diverge from each other at $55^{\circ}$. The bulbous appearance of the tracts as they diverge suggest that sessile olfactory bulbs may have been housed here. The telencephalic region has straight dorsal and ventral margins, although ventrally this angles steeply upwards towards the olfactory bulbs suggestive of a slight telencephalic expansion in this region ventrally. An anterodorsally-extended eminence on the dorsal surface represents the space for the pineal organ and stalk, and two ventral expansions below this likely housed the optic nerves. The mesencephalic region is similarly high and narrow as is the forebrain.

On either side of the endocast, just anterior of the labyrinths, two laterally-extended protrusions probably housed the trigeminal nerve complex. The roof of the cranial cavity is mostly flat and straight in the hindbrain region, and sitting lower than the anterior semicircular canals. A small bulge dorsally in the metencephalic region probably represents the space for the endolymphatic ducts.

The arrangement of the semicircular canals appear somewhat unusual for Devonian lungfishes in that the anterior canal is noticeably longer than that of the posterior canal. The anterior semicircular canals are anterior-posteriorly extended, whereas the posterior canals are shorter and are more dorso-ventrally oriented. The lateral semicircular canal has a strong curve and re-enters the labyrinth anterior to the posterior canal. The utricular recess is well-defined on both sides of the specimen, forming almost spherical extensions of the vestibule. Ventral to this, the sacculus forms a single chamber (without a notch to separate the lagena) appearing as an elongated oval-shaped region.

\section{Orlovichthys limnatis (PIN 3725/110).}

The endocast of Orlovichthys limnatis measures just over $50 \mathrm{~mm}$ in length and $20 \mathrm{~mm}$ in width (Supplementary Figure 3). The right-hand side is better preserved and includes a complete labyrinth. The nasal capsules (left-hand side preserved) are small and semicircular in outline. The olfactory canals are very short and diverge at $50^{\circ}$ from each other. However, overall the forebrain (comprising the olfactory lobes, telencephalon and diencephalon), is extremely long and narrow.

The hypophyseal fossa for the hypothalamus extends posteroventrally and there is only a small protrusion for the pineal eminence dorsally. The canal housing the pseudobranchial artery exits the hypophyseal recess latero-ventrally before abruptly turning postero-laterally. It does not bifurcate into separate canals for the pseudobranchial and internal carotid arteries. In the anterior region of the hypophyseal recess two short canals projecting anteriorly likely housed the palatine arteries. Dorsal to the canals for the pseudobranchial/internal carotid arteries a slender canal projects antero-laterally. This canal held the ophthalmic artery. Just posterior to this canal, the canal for the pituitary veins project laterally and slight dorsally. 
bioRxiv preprint doi: https://doi.org/10.1101/2021.09.13.460037; this version posted September 15, 2021. The copyright holder for this preprint (which was not certified by peer review) is the author/funder, who has granted bioRxiv a license to display the preprint in perpetuity. It is made available under aCC-BY 4.0 International license.

180

181

182

183

184

185

186

187

188

189

190

191

192

193

194

195

196

197

198

199

200

201

202

203

204

205

206

207

208

209

210

211

212

213

214

215

216

217

218

219

220

221

222

223

224

The dorsal margins of the telen-, dien- and mesencephalon regions are incomplete but appear to have been relatively flat. The optic nerve canals (n.II) exit antero-laterally from just behind the pronounced subpallium of the telencephalon. Slightly dorsal and posterior to n.II is a small canal that exits perpendicular to the lateral wall of the mesencephalon and represents the canal for the oculomotor nerve. A canal for the trochlear nerve is not visible. The trigeminal nerve complex exits the cranial cavity branching into two separate canals extending anterolaterally. $O$. limnatus lacks highly expanded space to house the endolymphatic ducts as is present in some other taxa (e.g. ' $C$ '. australis, $R$. kimberleysensis), but the posterior extend of the supraoptic cavities are visible. A canal for the abducens nerve (n.VI) projects anteriorly from the anterior of the saccule.

The labyrinth system comprises three semicircular canals, each bearing prominent ampullae and forming small, circular arcs. The point where the anterior and posterior semicircular canals join, the crus commune, sits above the roof of the cranial cavity. $O$. limnatus has a prominent, oval-shaped utriculus and an elongated sacculus pouch, which is inferred to have been large although it is incomplete ventrally.

\section{Pillararhynchus longi (ANU 49196) - with additional notes on Gogodipterus paddyensis (WAM 70.4.250).}

Due to their similarity and incompleteness of Gogodipterus, the following description is based predominantly on Pillararhynchus, but where features differ in Gogodipterus further remarks are included. Gogodipterus paddyensis was previously described as Chirodipterus paddyensis (Miles 1977), before the material was further acid-prepared and redescribed as Gogodipterus by Long (1992b). Only the inner ear canals and part of the trigeminal nerve complex are preserved as it is missing a large part of the dorsal and anterodorsal faces of the endocranium.

As noted in Barwick \& Campbell (1996), Pillararhynchus longi (ANU 49196) is seemingly a small and was presumably a young individual with the following measurements: skull $46 \mathrm{~mm}$ long, $33 \mathrm{~mm}$ wide and 31 $\mathrm{mm}$ high (Supplementary Figure 4). The braincase is well preserved but most of the skull roof is missing. The endocast itself measures $38 \mathrm{~mm}$ in length. In comparison, Gogodipterus paddyensis (WAM 70.4.250) was a larger individual and although incomplete anteriorly, had a skull at least $75 \mathrm{~mm}$ in width (Supplementary Figure 5). The holotype is also lacking dermal skull bones, but the oticoccipital region of the braincase is well preserved and allows for comparison of this region with other taxa.

The nasal capsules are large, oblong, with a convex dorsal surface and remain open ventrally. There are no discernible divisions within the two capsules. The large canals for the olfactory nerves (n.l) enter the nasal sacs in their posteromediodorsal region. Below these nerves, there are two other canals exiting the nasal capsule posterolaterally; the larger canal likely contained the orbitonasal vein, and smaller canal likely contained the palatine nerve (VII). The olfactory canals diverge at around $45^{\circ}$ from each other. They remain relatively narrow except for a slight bulge just anterior of where they join the telencephalic region, suggesting that these swellings housed sessile olfactory bulbs. On the right side, there is a single canal exiting dorsally from one of these swellings, before changing course to an anterolateral direction. This may represent a branch of the anterior cerebral vein.

The forebrain region is narrow but dorsoventrally raised. It is dominated by a large single recess for the pineal organ, extending anterodorsally over the junction of the olfactory canals and the telencephalon. In line with the pineal eminence, but situated ventrally, are the two large olfactory canals. Anterior to these in 
ventral view, a slight swelling for the telencephalon can be seen. In the diencephalic region the hypophyseal recess extends directly ventrally beneath the cranial cavity. Two pairs of canals exit the hypophysis; furthest ventrally and extending anterolaterally is the canal for the ophthalmic artery, and those extending directly laterally carried the pituitary vein.

The midbrain is wider than the preceding forebrain but much shallower. The dome for the mesencephalon represents the highest dorsal extent of the cranial cavity. On the left side of the specimen, a small canal situated midway up the cranial cavity wall would have housed the oculomotor nerve (n.III), and further dorsal to this is another opening, which may represent the remains of the trochlear canal (n.IV).

The anterior metencephalic region is marked by a large bifurcating canal for the trigeminal nerves $\left(n . V_{1}\right.$ and $\left.n . V_{2 \& 3}\right)$ projecting laterally. Just posterodorsal to these are the similarly large canals for the facial nerves (n.VII), which soon reconnect with $n . V_{2 \& 3}$. The dorsal extent of the rhombencephalon is flat and broad, and significantly lower than that of the mesencephalon and labyrinth with the exception of the two rounded protuberances of the supraotic cavities. There are no obvious endolymphatic ducts in P.longi, although one is present on the right side in G. paddyensis. The roof of the rhombencephalic portion of the cranial cavity in $G$. paddyensis is also not as flat as that of $P$.longi. Two large canals posterior to the labyrinths house the vagus nerves (n.X), and several other smaller canals in this region would have carried smaller spinal nerves. Ventral to the cavity for the spinal cord and separated by bone is the large notochordal canal although the anterior-most extent of the canal cannot be gleaned from the scan data due to very bright pyritic inclusions in the specimen obscuring this and the form of the sacculolagenar region.

The labyrinth region on the right side is well preserved, containing all three semicircular canals and the utricular recess. Unfortunately, the boundaries of the sacculolagenar pouch are not observable and thus its shape cannot be reliably determined. The semicircular canals are robust and form small circular arcs; although the arcs in $P$. longi are slightly more ovoid than those of $G$. paddyensis. Each canal possesses a sizeable expansion (ampulla) at its base. The crus commune is situated ventral to the highest points of the anterior and posterior semicircular canals, and the sinus superior is also prominent above the roof of the cranial cavity. The posterior canal is the longest of the three semicircular canals, joining with and at the level of the lateral canal, rather than inserting on top of it as the anterior semicircular canal. The lateral canal is the shortest of the three semicircular canals. Although the sacculolagenar region is not preserved, by comparison with the semicircular canals, the spherical utricular recess appears relatively small. The semicircular canals of $G$. paddyensis are well preserved but almost indistinguishable from those in $P$. longi.

\section{Rhinodipterus ulrichi (NRM P6609a).}

The endocast of Rhinodipterus ulrichi is incomplete anteriorly without the nasal capsules preserved (Supplementary Figure 6). Overall, the endocast is extremely narrow (14 $\mathrm{mm}$ in length and would have been only about $5 \mathrm{~mm}$ wide in life), although the specimen has undergone some lateral compression. Only the left olfactory canal is preserved so the angle of divergence between them is not known, although it appears to have been very small.

The long and narrow olfactory canal runs directly anteroposteriorly before reaching the telencephalon which bears a prominent ventral bulge and a steeply posterodorsally-angled dorsal margin (which continues to rise all the way up to the mesencephalic portion of the endocast). There is a large pineal eminence projecting anterodorsally from the roof of the diencephalic region. The hypophyseal fossa is of moderate size and 
extends posteroventrally from the lower margin of the endocast. The large, circular canals for the optic nerves (n.II) are visible close to the ventral boundary between the telencephalic and diencephalic regions. Smaller canals that would house nerves n.III (oculomotor) and n.IV (trochlear) exit the cranial cavity close to the ventral margin of the mesencephalic region.

The mesencephalic region is unusual in being the highest point of the endocast with a dorsal bulge in this area. The divergence between the rostral forebrain and caudal hindbrain is large at $140^{\circ}$ and seemingly unusual in lungfishes with the condition not known in any other taxon.

On the right side of the specimen, it appears there may have been space for enlarged supraoptic cavities in Rhinodipterus ulrichi, similar to the condition in R. kimberleyensis. The dorsal margin of the hindbrain is similarly domed as is the midbrain, although not as distinct. The bifurcating canal for the trigeminal complex is best visible on the right-hand side, as is the canal posteriorly for the vagus nerve (n.X).

The anterior and lateral semicircular canals are preserved on the left side, but only the anterior canal appears to bear an ampullar swelling, where it connects with the utriculus. The utricular recess is relatively large and is somewhat lemniscate in outline when viewed laterally. The sacculolagenar pouch is elongate and tapers posteriorly. The notochordal canal is preserved between the two sacculolagenar pouches and extends anterior to the level of the trigeminal nerve complex.

\section{Principal Component Analyses}

Firstly, preliminary classical PCAs were performed on partial matrices in order to maximize either the number of variables (13 variables on seven taxa) or the number of taxa (nine variables on nine taxa); for such analyses no methods of imputation were used. In both analyses, the most incomplete taxa (i.e., Griphognathus whitei, Protopterus aethiopicus, Gogodipterus paddyensis, Dipnorhynchus sussmilchi and Rhinodipterus ulrichi) were excluded, thus results from these analyses do not encompass the whole spectrum of disparity (Supplementary Figures 7-8). Results from PC1 and PC2 were interpreted based on the broken stick method.

In the PCA maximizing the number of characters, most variables (with the exception of the angle between the olfactory canals and the height of $n . I I$ foramen) are increasing simultaneously accounting for $55.2 \%$ of the total variation, whereas the variation associated with the angle between the olfactory lobes and height of n.ll foramen accounts for the variation of PC2 (16.4\%). In the PCA maximizing the number of characters, variables associated with the semicircular canals (height, length, and width) and variables taking into consideration that nerves (n.II, n.V, n.X) position covaried together and represent $69.9 \%$ of the total variation. The second axis reflects a contrast between the length of the olfactory canals and the angle between these canals and it accounts for $17.1 \%$ of the total variation. In both classical PCAs, some variables cluster together [(1) the three variables (length, height and width) of the semicircular canals, and (2) the depth at nerves II and V] and the angle between the olfactory lobes show a clear distinction from the remaining variables.

Secondly, using Bayesian PCA (BPCA), only two axes are considered to be statistically non-trivial based on their eigenvalues (Figure 2). The first axis accounts for $48.6 \%$ of the variation, whereas the second axis explains $33.5 \%$. The main source of variation of the first axis is a contrast between the length of the nasal capsules and the olfactory canals, and the angle between the olfactory canals. All the remaining variables 
respond similarly (all change concordantly with the tandem length of the nasal capsules - length of the olfactory canals) corresponding to a minor source of variation for axes 1 and 2 . The length and angle of the olfactory canals still represent an important source of variation on the third axis $(12.0 \%$ of the variation, Figure $2 \mathrm{~b}$ ). In summary, BPCA 1 and 2 summarize the general endocranial tendency, whereby the length of the nasal capsule + olfactory canals increase as the angle between the olfactory canals decreases.

Griphognathus whitei has a particularly strong weight on this tendency (Figure 2a).

Further findings worthy of note include Gogodipterus paddyensis failing to cluster near the rest of the 'chirodipterids', instead plotting out closer to some of the more basal taxa, Dipnorhynchus sussmilchi and lowadipterus halli. The extant taxa, Neoceratodus and Protopterus do not share a similar morphospace, whereas Chirodipterus australis, Dipterus valenciennesi, Orlovichthys limnatis and Rhinodipterus spp. do (Figure 2a).

Next, using the PCA method for incomplete data (InDaPCA), the first axis represents $66.0 \%$ of the variation, while the second, third and fourth axes represent $12.6 \%, 6.46 \%$, and $4.62 \%$ of the variation, respectively (Figure 3). Based on the scree plot, the first three axes are non-trivial, but the interpretation of the fourth axis is also biologically meaningful (Supplementary Figure 9). The main difference between the scatter diagrams of the InDaPCA and the BPCA is that the taxa in the PCA for incomplete data morphospace occupy a better space distribution.

The first axis in the InDaPCA corresponds to an integration of all variables with the exception of the angle between the olfactory canals (Figure 3, Supplementary Figure 9a), which has a weak importance on the first axis. This main source of variation corresponds to a coordinate integration of the endocast components. Axis 2 reflects mainly the contrasts between (1) the length of the olfactory canal and the angle between these canals, (2) the size and shape of the sacculus and utriculus, and (3) the distance between cranial nerves $V$ and $X$ and the height of the foramen for cranial nerve $V$. The main contrasts on axis 3 corresponds to (1) the angle between the olfactory canals versus the length of these canals, and (2) the distance between cranial nerves $V$ and $X$ and the semicircular canal parameters versus the depth of cranial nerves II and IV and the height of the foramen of cranial nerve V. Projections of axes 2 versus 3, 2 versus 4, and 3 versus 4 are more informative to decipher neurocranial changes.

For all the different projections (axes 1 versus 2, 1 versus 3, 1 versus 4, 2 versus 3, 2 versus 4 and 3 versus 4), some variables cluster together: (1) the three variables (length, height and width) of the semicircular canals, (2) the height and length of the sacculus, (3) the height and length of the utriculus and to a lesser extent (4) the depth at cranial nerves II and V. On axes 2 and 3, the height of the foramen for cranial nerve II, the distance between cranial nerve II and the olfactory bifurcation and the length of the nasal capsule do not contribute to the main source of variation. On the projection of axes 2 versus 3 as well as axes 2 versus 4 , there is a consistent signal that the sacculus is better integrated with the semicircular canals and opposed to the utriculus. Thus, when the parameters associated with the sacculus and semicircular canals increase the parameters for the utriculus decrease. Although when these parameters are combined it is part of a complex system, these results suggest a modular dissociation. 


\section{DISCUSSION}

Lungfish first appear in the fossil record in the Early Devonian as robust marine animals, many with hypermineralised tooth plates, heavily-ossified dermal skulls and neurocrania. However, from the Late DevonianCarboniferous onwards, many undergo a decline in the degree of ossification as their skeleton becomes more cartilaginous. This reduction in the dipnoan cranial dermal skeleton was likely accompanied by some changes in the cranial cavity form, but this level of increasingly poor ossification of the neurocranium in such taxa limits our possible comparisons to between the more heavily ossified Devonian forms and extant taxa only. Consequently, some of the oldest lungfish taxa are the most completely known, especially with respect to neurocranial morphology. No post-Devonian fossil taxa have had their cranial endocasts described.

\section{Implications for sensory abilities in early lungfishes}

Overall, there is considerable variation in the form and relative proportions of the endocasts examined (Figure 1). Griphognathus whitei stands out as the most extreme case of elongation of the olfactory region, whereas other taxa, such as lowadipterus halli, appear to elongate the midbrain region, whilst retaining very short olfactory canals and more conventionally-shaped nasal capsules (rounded to slightly oval). Although only a partial endocast, Gogodipterus paddyensis is nearly indistinguishable from Pillararhynchus longi in labyrinth morphology. All 'chirodipterid' taxa (sensu Friedman 2007) appear to share mediolaterally-oriented nasal capsules, close to equidimensional circular arcs of their semicircular canals and a broad angle of bifurcation between the olfactory canals. Rhinodipterus ulrichi and 'Chirodipterus' australis have endocasts with strongly anteroventrally-directed fore/midbrain portions in comparison with the hindbrain, while presumed close relatives $R$. kimberleyensis and other 'chirodipterid' taxa do not display this character. Aside from this, the endocasts of the two Rhinodipterus species are broadly similar to each other - the absence of an eminence for the pineal organ in R. kimberleyensis is likely a preservational artefact (Clement \& Ahlberg 2014). The hypophyseal recess varies from being directed ventrally (R. kimberleyensis, Orlovichthys limnatis, P. longi) or posteroventrally (Dipnorhynchus spp., Dipterus valenciennesi, R. ulrichi).

The length of the olfactory canals (usually incorporating olfactory nerve, bulb and tract) and their angle of bifurcation are one of the largest sources of variation between endocasts of different lungfish taxa, and unsurprisingly, these two features are strongly linked. The other strongest signals from our data concern the labyrinths, specifically the size and shape of the sacculus, utriculus and the semicircular canals. The semicircular canals (arc height, length and width) tend to covary as an integrated module, whereas the utriculus and sacculus vary independently of each other. The sacculus is better integrated with the semicircular canals than the utriculus, suggesting a modular dissociation. Taken together, our analyses suggest that the olfactory and labyrinth regions are more highly plastic and may reflect species differences in chemosensory and auditory abilities, whereas the hindbrain is more conserved. These findings are interesting as the olfactory region seems to be changing independently from all other endocast variables, despite elongated dermal crania being modified in different ways (e.g. elongation of the dermal snout, cheek or jaws). A similar finding has been established for extant cartilaginous fishes, where the olfactory bulbs maintain a substantial level of allometric independence from the rest of the brain in more than 100 species, reflecting differences in ecological niche, particularly habitat (Yopak et al. 2015; Yopak et al. 2019), a relationship which is common to other vertebrates (Yopak et al. 2010). This suggests that these species of lungfishes may have had different olfactory abilities for various survival tasks including localizing prey, avoiding predators, and chemosensory communication with conspecifics. 
The inner ears are comprised of a superior division containing the semicircular canals, which are predominantly involved in balance perception, and whose morphology is closely correlated with an animal's agility and orientation within the water column, sensitivity to movement and even visual acuity (Kemp \& Kirk 2014; Malinzak et al. 2012; Spoor et al. 2002). In contrast, the inferior division, or vestibule, contains the sacculus and utriculus, which are sensitive to mechanical acceleration, but also play an auditory role in discriminating and localising sound. Inner ear morphology in fishes tends to be relatively conserved, and when there is variation it is more commonly seen in this inferior division rather than the semicircular canals (Ladich \& Schulz-Mirbach 2016). The sacculus (combined with the lagena in lungfish), is most sensitive to movements in the vertical plane, whereas the utriculus detects angular and linear acceleration predominantly in the horizontal plane (Platt et al. 2004). Similar bioimaging techniques and consequent morphometric analyses have been used to successfully predict both auditory and vestibular abilities in other aquatic vertebrates (Lauridsen et al. 2011; Ramcharitar et al. 2004; Willis et al. 2013).

With soft tissues, such as brains, typically not fossilising, there is a need to use endocasts as proxies to infer or reconstruct gross neural morphology in extinct taxa (Clement et al. 2016b). With respect to making meaningful biological inferences from lungfish endocasts, evidence from extant lungfish show a moderate correspondence between brain and endocast in life (Challands et al. 2020; Clement et al. 2015). Interestingly, there tends to be considerably higher correspondence in the forebrain and labyrinth regions (Clement et al. 2015), and we thus can have more confidence in potential functional interpretations relating to those regions. Fortuitously, it is in those regions where we see the largest variations in our analyses, highlighting the potential to elucidate functional and biologically significant insights.

Thus, guided by our findings and the Principle of Proper Mass (Jerison 1973), we believe we can draw some reasonable conclusions about brain evolution in lungfishes. The hindbrain region appears to have remained relatively conserved throughout lungfish evolution, and there is no evidence of hypertrophy as is seen in some other lineages, i.e. within the Chondrichthyes and Actinopterygii (Nieuwenhuys et al. 1998; Striedter \& Northcutt 2020). The midbrain similarly seems to have remained relatively small and it seems unlikely that vision has ever been a dominant sense in lungfishes (in contrast to many actinopterygians). The forebrain underwent early expansion in some of the oldest members of the lineage and appears to have continued to present day, suggesting an ongoing and increasing reliance the role of olfaction. Relatedly, the high variability in this region throughout their evolutionary history highlights continuing modification of and importance in the role of olfaction in lungfishes. And finally, the changes seen in the labyrinth region, particularly the expansion of the utriculus, suggests increasing sensitivity to auditory input and/or movements in the horizontal plane, probably reflecting changing sensory requirements from deeper water marine environments in the earliest lungfishes, to more terrestrial ecosystems among Mid-Late Devonian members to present day taxa.

\section{Taxonomy of the 'chirodipterids'}

The genus Chirodipterus was erected by Gross (1933), and the first lungfish endocast to be described was that of $C$. wildungensis from the Upper Devonian in Germany (Säve-Söderbergh 1952). Since that time, several more species of Chirodipterus have been described, including forms from Europe (Mörs 1991; SäveSöderbergh 1952), China (Song \& Chang 1991), USA (Schultze 1982) and Australia (Kemp 2000; Miles 1977). Other so-called 'chirodipterids' (sensu Friedman 2007) include Pillarahynchus (Barwick \& Campbell 1996) and Gogodipterus (Long 1992b) from Australia, and Sorbitorhynchus (Wang et al. 1993) from China, suggesting a wide global distribution. 
However, recently was been noted that Chirodipterus may in fact form a paraphyletic group, as first noted by Friedman (2007), with the various species failing to be recovered as closely related in subsequent phylogenetic analyses (Challands et al. 2019; Clement 2012; Qiao \& Zhu 2009). The use of endocast characters to infer phylogeny has proved valuable in tracing the evolution of lungfish (Clement et al. 2016a; Friedman 2007), and so further analysis of 'chirodipterid' endocasts is likely to provide valuable data to clarify the taxonomy of this problematic genus.

The reconstruction and interpretation of the endocast of Chirodipterus wildungensis by Säve-Söderbergh (1952) was a valuable contribution to palaeoneurology as the first account of the endocranial structure of a fossil dipnoan. Yet, by the author's own admission, it was heavily influenced by comparison with the extant Australian lungfish (Neoceratodus). His interpretation that $C$. wildungensis had "a cranial anatomy astonishingly closely comparable to that of... Neoceratodus" (Säve-Söderbergh 1952, pg. 28), and subsequent conclusion by Stensiö (1963, pg. 82) that its "cranial anatomy ... agrees surprisingly well with Neoceratodus" are at odds with the morphology 10 Devonian taxa analysed in this work and recent studies of extant Australian lungfish endocrania (Challands et al. 2020; Clement et al. 2015). We argue that it seems more likely that the similarities with extant lungfish were (unintentionally) overstated, and the true morphology of $C$. wildungensis was probably more similar to that of other Devonian lungfishes. Sadly, the condition of the original specimen precludes the possibility of us adequately testing this hypothesis at this time.

Two of the specimens included in our study, Pillararhynchus longi and Gogodipterus paddyensis, possess the snub-nosed morphology commonly found among 'chirodipterids', and four other taxa are known from 3Danalyses of preserved material, which should enable their endocasts to be reconstructed. Of these six 'chirodipterids' (also those that are commonly included in phylogenetic analyses of Palaeozoic lungfishes), the endocast of 'Chirodipterus' australis is already known (Henderson \& Challands 2018). Pillararhynchus longi and Gogodipterus paddyensis are investigated as part of this study and Chirodipterus wildungensis was studied and CT scanned but unfortunately found not to be amenable to further study (Clement, pers. comm.). This leaves the two Chinese taxa, Sorbitorhynchus deleaskitus and Chirodipterus liangchengi, currently under examination (T. Qiao, IVPP, pers. comm. August 2019).

Our findings, and data from the Chinese taxa once published, should thus enable definitive clarification of the taxonomy of Chirodipterus. Nevertheless, from our current work we can already identify several characters common to 'chirodipterids' (such as a prominent pineal process, mediolaterally-oriented nasal capsules, a ventrally-directed hypophyseal region, near-equidimensional circular arcs of all three semicircular canals), which should be tested in any further studies of chirodipterid taxonomy.

\section{Elongated crania}

At the other end of the morphological spectrum from the 'chirodipterids', the development of an elongated snout and/or skull has occurred convergently across many genera of actinopterygians but is not a wellestablished morphology in piscine sarcopterygians. In fact, lungfish are the only sarcopterygian group that developed significant cranial elongation, and those that did were mostly confined to the Mid to Late Devonian (ranging from the Givetian to the Famennian). 
Of those that developed this condition, Schultze (1992) recognised that it has been achieved in a number of different ways: elongation of the anterior dermal bones and the mandible (Griphognathus, Soederberghia, Rhynchodipterus and possibly Jarvikia and Fleurantia); development of a longer series of posterior dermal and cheek bones (lowadipterus); or elongation of the mandibular symphysis (Rhinodipterus). Additionally, Orlovichthys possesses elongate anterior rostral bones but a short mandible and large mandibular symphysis. We collectively refer to these taxa as having elongate crania rather than being 'long-snouted' or 'long-headed' in recognition that the condition is achieved in different ways.

Stensiö's (1963) hypothesis that the dipnoan brain type was established by the Early Devonian is somewhat surprising given that he would have been familiar with forms with elongated crania such as Soederberghia, Rhinodipterus, Rhynchodipterus and Oervigia. However, the renaissance in dipnoan research during the 1970s and 1980s - largely driven by Roger Miles, Hans-Peter Schultze, Ken Campbell and Dick Barwick - had not yet occurred and as such, the full diversity of forms we now recognise were unknown to him. Stensiö's assertion that "the Dipnoan brain had ... remained practically unchanged" (Stensiö 1963, pg. 82) was challenged recently by Clement \& Ahlberg (2014) and is similarly tested by this study.

Devonian lungfish with elongate crania fail to form a distinct clade, but rather a paraphyletic group that have converged towards head elongation. Schultze (1992) recognised two groups of long-snouted dipnoans: the rhynchodipterids (Griphognathus, Rhynchodipterus, Soederberghia) plus Fleurantia and Jarvkia and the genus Rhinodipterus. These two groups are differentiated by the former being denticulated forms and the latter possessing tooth plates representing different means of feeding. Despite the elongation of the lower jaw in Rhinodipterus, the mechanical advantage is similar to other tooth-plated lungfish and different from forms with long crania and denticulate dentition (Clement 2012).

The rhynchodipterids were resolved by Marshall (1986) following analysis of Holodipterus and Fleurantia which in turn were found to be sister taxa to Jarvikia, a grade forming the most derived Devonian dipnoans below Carboniferous forms. Friedman (2007) resolved rhynchodipterids as the sister group to Chirodipterus wildungensis in a detailed analysis that incorporated new characters of the endocranium. More recent analyses (Challands et al. 2019) have provided a more nuanced picture by including more taxa with elongate crania and have confirmed that the rhynchodipterids form a monophyletic group (albeit placed in a more basal position), and also that the 'rhinodipterids' are monophyletic (although with the likely exception of ' $R$.' stolbovi). Fleurantia and Apatorhynchus are grouped together in a relatively derived position close to the majority of Carboniferous lungfishes.

Other forms with elongate crania are placed in isolated positions alongside short-snouted taxa, and interestingly Orlovichthys and Jarvikia were found to resolve in the same clade along with taxa with short crania and tooth-plated dentition. lowadipterus is the most basal of the lungfish with an elongated head, representing a unique solution to the morphology.

The elongation of lungfish crania has been proposed to be related to either feeding functional morphology (Campbell \& Barwick 1986; Sharp \& Clack 2013) or air-gulping ability (Gess \& Clement 2019, and other references therein). As mentioned earlier, this cranial elongation is achieved via various approaches, either by modification of the dermal bones in the snout, cheek, or in the jaws. Thus, we expected that the neurocranium and endocasts of Devonian lungfishes would have also accommodated elongation via different approaches. In contrast, we found that it is nearly always the olfactory region that is elongated 
regardless of which portion of the dermal skull appears to lengthen, and that the hindbrain remains relatively conserved in form. The most glaring exception to this is that of lowadipterus which appears to have very short olfactory canals but a long and narrow midbrain. We believe further consideration of this unusual taxon is warranted.

\section{CONCLUSIONS}

The cranial endocasts of six Palaeozoic dipnoans (lowadipterus halli, Gogodipterus paddyensis, Pillararhynchus longi, Griphognathus whitei, Orlovichthys limnatis, and Rhinodipterus ulrichi) are created and described from synchrotron and computed tomography (CT) data. These represent a significant addition to the other known Palaeozoic lungfish endocasts (previously only four virtual endocasts had been described from tomographic data, and four others with partial endocasts were described and reconstructed directly from observation of specimens). Morphometric analyses of 10 Palaeozoic and two extant lungfish genera are conducted using Bayesian Principle Component Analysis (BPCA) and PCA for incomplete data (InDaPCA), which show the olfactory and labyrinth regions exhibit the largest amount of variation. Functional interpretation suggests that olfaction remains one of their most dominant senses throughout lungfish evolutionary history. The phylogenetic implications for the 'chirodipterids' and long-headed lungfish are discussed, and we support incorporation of additional endocranial characters in future analyses of dipnoan interrelationships.

\section{MATERIAL \& METHODS}

\section{Specimens Examined}

Six species of Devonian lungfish were examined this this study: Gogodipterus paddyensis (WAM 70.4.250); Griphognathus whitei (NHMUK PV P56054); lowadipterus halli (FMNH PF 12323); Orlovichthys limnatis (PIN 3725/110); Pillararhynchus longi (ANU 49196); Rhinodipterus ulrichi (NRM P6609a).

\section{Imaging and Segmentation}

\section{Gogodipterus paddyensis (WAM 70.4.250).}

Gogodipterus paddyensis was scanned using X-ray micro-computed tomography (X-ray $\mu \mathrm{CT}$ ) at the Centre for Microscopy, Characterisation and Analysis (CMCA) at The University of Western Australia (UWA) in Perth, Australia in 2019. Parameters used were 80kV and 7W using a Versa 520 XRM (Zeiss, Pleasanton, CA, USA). An LE2 beam filter was used to mitigate beam hardening and increase contrast. Source-sample and sampledetector distances were set to -73 and $48 \mathrm{~mm}$, respectively, which together with the $0.4 \mathrm{X}$ objective and $2 \mathrm{x}$ camera binning, resulted in a final pixel resolution of $41.52 \mu \mathrm{m}$. Suitable image intensity was achieved with an exposure of $1 \mathrm{~s}$ and a total of 2401 projections were collected through $360^{\circ}$ for the tomography. Owing to its large size, the sample was scanned in wide stitch mode, with five vertical segments needed to cover the full height. In addition, auto referencing was disabled, with a single reference collection captured prior to scanning. Reconstruction and stitching were achieved automatically by the software using default settings. Total scan time was $21 \mathrm{~h} 38 \mathrm{~min}$. These data were manually segmented and rendered in MIMICS V.19 (Materialise).

\section{Griphognathus whitei (NHMUK PV P56054).}

Griphognathus whitei was scanned at the Natural History Museum, UK, using a Nikon Metrology HMX ST 225 micro-CT scanner. The specimen was scanned with the following parameters: Energy $210 \mathrm{KeV}$, voxel size 102 microns, 180 degrees, 3142 proj, angle step $0.1 \mathrm{deg} / \mathrm{proj}$, exposure time $0.5 \mathrm{sec} / \mathrm{proj}$, object to detector 
$1170 \mathrm{~mm}$. (filters: $2.5 \mathrm{~mm} \mathrm{Cu}$ ). The resulting image stack was rendered and segmented manually using Drishti and Drishti Paint 2.6.1 to produce a virtual 3D endocast.

\section{lowadipterus halli (FMNH PF 12323).}

The holotype and only known specimen (FMNH PF 12323) was scanned at The University of Texas HighResolution X-ray CT Facility, Austin, in 2007 using the following parameters: 419 kV, $1.8 \mathrm{~mA}, 130 \%$ offset, 1 brass filter, air wedge, integration time $128 \mathrm{~ms}$, slice thickness $0.25 \mathrm{~mm}$, S.O.D. $700 \mathrm{~mm}, 2000$ views, 1 ray averaged per view, 2 samples per view, inter-slice spacing $0.25 \mathrm{~mm}$, field of reconstruction $180 \mathrm{~mm}$ ( maximum field of view $184.9855 \mathrm{~mm}$ ), reconstruction offset 4000, reconstruction scale 4000. Total slices $=$ 192 , and resultant voxel size is $0.361 \mathrm{~mm}$. Segmentation was performed using MIMICS v.17 \& v.19 (Materialise).

\section{Orlovichthys limnatis (3725/110).}

Orlovichthys limnatis was scanned at the Palaeontological Institute, Moscow, in three sections using a Skyscan 1172 micro-CT scanner. Each section was scanned with the following parameters: Energy $100 \mathrm{KeV}$, voxel size 34.1 microns, 180 degrees, 514 proj, angle step $0.7 \mathrm{deg} / \mathrm{proj}$, exposure time $0.79 \mathrm{sec} / \mathrm{proj}$, object

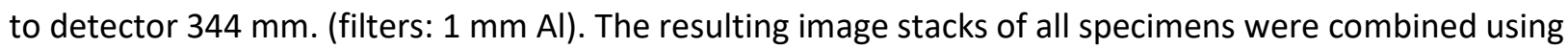
ImageJ and the subsequent image stack was rendered and segmented manually using Drishti and Drishti Paint 2.6.1 to produce a virtual 3D endocast.

\section{Pillararhynchus longi (ANU 49196).}

Pillararhynchus longi was scanned at the Australian Synchrotron (Australian Nuclear Science and Technology Organisation, ANSTO), during experiment number AM10403 in 2016 with the following parameters: Energy $40 \mathrm{KeV}$, voxel size 12.2 microns, 181 degrees, 1810 proj, angle step $0.1 \mathrm{deg} / \mathrm{proj}$, exposure time 0.22 $\mathrm{sec} / \mathrm{proj}$, object to detector $35 \mathrm{~mm}$. (filters: $0.45 \mathrm{~mm}$ carbone $+5 \mathrm{~mm}$ high density Carbone $+10 \mathrm{~mm}$ high density Carbone $+1 \mathrm{~mm} \mathrm{Al}+1 \mathrm{~mm}$ Al?). The resulting image stacks of all specimens were rendered and segmented manually using MIMICS v.18 and v.19 (Materialise) to produce a virtual 3D endocast.

\section{Rhinodipterus ulrichi (NRM P6609a).}

Rhinodipterus ulrichi was scanned at the European Synchrotron Radiation Facility (ESRF) on beamline ID19 using propagation phase-contrast X-ray synchrotron radiation micro-computed tomography (PPC-SR $\mu \mathrm{CT}$ ) and the attenuation protocol of Sanchez et al. (2013) with 4 meters between the sample and detector. It was imaged with $90 \mathrm{keV}$, with 4000 projections over 360 degrees of 0.1 second each, in half-acquisition mode. Two columns of 30 scans each were required to capture the entire specimen, which had a resultant voxel size of $30 \mu \mathrm{m}$. The endocast was rendered and manually segmented in Drishti Paint 2.6.1.

Note: The first lungfish to have had its endocast described (Säve-Söderbergh 1952) was Chirodipterus wildungensis, Gross 1933, which is currently housed in the Museum für Naturkunde in Berlin, Germany (MB.f 12875 , holotype). One of us (AMC) visited Berlin to examine and scan this specimen in December 2018. The original 'shatter method' dissection of the specimen resulted in some $\sim 70$ separate pieces of the skull, but only about 10 sizeable pieces remain in the collection today, possibly due to loss or degradation. The largest three blocks were scanned at the $\mu \mathrm{CT}$ Lab of Museum für Naturkunde using the following parameters: "c" 140kV, 500uA, 2000 proj., 360 rotation, 0.139 pixel size; "cd" 100kV, 135uA, 2000 proj., 360 rotation, 0.139 pixel size; "f" 100kV, 135uA, 2000 proj., 360 rotation, 0.139 pixel size. Despite this, we unfortunately did not 
find it possible to reconstruct endocranial morphology from the scanned or remaining segments of this specimen.

\section{Measurements and Analysis}

Endocast dimensions (Figure 2c) were taken using IC Measure on-screen calibration and measurement software (https://www.theimagingsource.com). The complete original matrix (SI-Table 1, sheet2) combined 17 endocast variables examined in 14 specimens representing 12 species ('Chirodipterus' australis and Dipterus valenciennesi were coded for two specimens each). This included 10 Palaeozoic as well as two extant species (Neoceratodus forsteri and Protopterus aethiopicus). Both specimens of ' $C$ '. australis were included in every analysis, whereas only specimen NHMUK PV P17410 of $D$. valenciennesi was retained in our analyses (the incomplete specimen NMS G.2004-10-1 of $D$. valenciennesi was excluded because it had undergone considerable compression and consequently did not cluster near the other specimen of Dipterus, instead always occupying an outlier position). Specimen NHMUK PV P56038 of ' $C$ '. australis and specimen NHMUK PV P17410 of $D$. valenciennesi are the only two specimens for which all variables are available. Gogodipterus paddyensis is the most incomplete specimen missing 11 measurements out of a total of 17 variables. The complete original matrix has $24.7 \%$ of missing data, while the complete matrix (excluding one specimen of Dipterus) has $21.2 \%$ of missing data. Data were $\log _{10}$-transformed to minimize differences among taxa.

The 17 measured endocast variables are defined as follows: ANG_OLF, angle of bifurcation between olfactory canals; D_NII, depth of cranial endocast at level of n.II; D_NV, depth of cranial endocast at level of n.V; DEP_HYP_F, depth of cranial endocast at level of hypophyseal fossa; HF_NII, distance from hypophyseal fossa to n.II; NAS_CAP_L, length of nasal capsules; NII_OLF_BIF, distance from $n$.II to point of bifurcation between olfactory canals; NV_HF, distance from n.V to hypophyseal fossa; NX_NV, distance from n.V to n.X; OLF_CAN_L, length of olfactory canals from nasal capsules to point of bifurcation; SAC_H, height of sacculus; SAC_L, length of sacculus; SCC_H, height of semicircular canals; SCC_L, length of semicircular canals from anterior to posterior; SCC_W, width of semicircular canals from midline to lateral canal; UTR_H, height of utriculus; UTR_L, length of utriculus.).

With respect to the first morphometric variable measured (ANG_OLF), we accept that olfactory nerves (n.I) lie between the olfactory epithelium within the nasal capsules and the olfactory bulbs, whereas olfactory tracts extend from the olfactory bulbs to the telencephalon. For simplicity, we herein refer to the entire length from the anterior of the telencephalon to the nasal capsules as the olfactory canals. Expansions within the olfactory canals are sometimes tentatively identified as the likely position of the olfactory bulbs, and can thus inform our interpretation of different taxa as having either a sessile or pedunculate arrangement. However, the angle of bifurcation between the olfactory canals is independent from olfactory bulb position in our analyses.

We used ordination methods to describe the variation and relationships among the endocranial variables. Preliminary classical principal component analyses (PCA) were performed on the correlation matrix (due to the different units of measurement used) of log10-transformed data to maximize either the number of taxa ( 9 taxa including both specimens of $C$. australis) or the number of variables (13 variables). Next, in order to contend with the incomplete data, we employed two methods: one with imputation (using assignment of values by inference), i.e. the Bayesian principal component analysis (BPCA), and one without imputation, i.e. 
PCA for incomplete data (InDaPCA). Both methods are designed to accommodate upwards of $15 \%$ of missing data.

Missing data were estimated using the Bayesian method developed by Oba et al. (2003) and implemented in the R package "pcaMethods" (Stacklies et al. 2007). A cross validation method was used to estimate the number of meaningful components - in this case the two first components (Stacklies et al. 2007). The InDaPCA method used was designed by Podani et al. (2021) and consists of a modified version of an eigenanalysis-based PCA for data containing missing values. The InDaPCA was performed in R using the correlation matrix. In this case, the four first components were considered for interpretation. Results from the preliminary classical PCA are briefly presented herein, but the main variation trends were congruent with both Bayesian PCA and PCA with incomplete data. The package "ggplot2" in R was used to create the graphics.

\section{ACKNOWLEDGEMENTS}

We thank Kristin Mahlow (Museum für Naturkunde, Berlin, Germany), Jeremy Shaw (CMCA at University of Western Australia, Perth, Australia), Anton Maksimenko (Australian Synchrotron, Melbourne, Australia), Paul Tafforeau (European Synchrotron Radiation Facility, Grenoble, France), Matthew Colbert (University of Texas High-Resolution X-ray CT Facility), the Palaeontological Institute, Moscow, Russia, and the Natural History Museum, London, UK, for scanning specimens. Additionally, we thank Sophie Sanchez, Daniel Snitting and Vincent Dupret (Uppsala University), and Matt Friedman (University of Michigan), for scanning and software support, or for providing access to beamtime. We are grateful to those who hosted collection visits and enabled access to specimens, including Alexey V. Pakhnevich (Russian Academy of Sciences, Moscow, Russia), Florian Witzmann (Museum für Naturkunde, Berlin, Germany), Mikael Siversson and Kate Trinajstic (Western Australian Museum, Perth, Australia), Lynne Bean and Gavin Young (Australian National University, Canberra, Australia), Zhu Min and Qiao Tuo (Institute of Vertebrate Paleontology and Paleoanthropology, Beijing, China). This work was supported by Australian Research Council grants DP160102460 (JAL, AMC), and DP200103398 (JAL, AMC, SPC), Flinders University (Impact Seed Funding to AMC, Visiting International Research Fellowships to RC \& TJC), a Wallenberg Scholarship from the Knut and Alice Wallenberg Foundation (PEA, AMC), and Callidus Services Ltd UK (TJC).

\section{AUTHOR CONTRIBUTIONS}

$A M C$ and TJC conceived and designed the project, segmented scan data, and wrote the first draft of the manuscript. AMC took measurements of endocasts and created figures. RC analysed the quantitative data and wrote portions of the manuscript. LH assisted with analyses and figures. PEA, RC and JAL provided materials and/or software. All authors contributed to the interpretation of results, edited a later version of the manuscript, and have approved a final version for submission.

\section{FIGURE LEGENDS}

Figure 1. Palaeozoic lungfish endocasts in dorsal, ventral, and left lateral views, placed onto phylogeny adapted from Challands et al. (2019). *The following endocasts were first published elsewhere but new images were created for inclusion in this figure: Rhinodipterus kimberleyensis (Clement \& Ahlberg 2014); 
Dipterus valenciennesi (Challands 2015); 'Chirodipterus' australis (Henderson \& Challands 2018);

Dipnorhynchus sussmilchi (Clement et al. 2016a).

Figure 2. Bayesian Principle Component Analysis (BPCA) biplot of lungfish endocast shape $\mathbf{A}$, between PCA 1 and PCA 2 with endocasts of Dipnorhynchus sussmilchi, lowadipterus halli, Chirodipterus australis, Pillararhynchus longi, Rhinodipterus kimberleyensis and Griphognathus whitei shown; and B, loadings for PCA 1-3 (PC1 R2=0.486, PC2 R2=0.335, PC3 R2=0.120); and C, illustration of 17 endocast variables measured. ANG_OLF, angle of bifurcation between olfactory canals; D_NII, depth of cranial endocast at level of n.II; D_NV, depth of cranial endocast at level of n.V; DEP_HYP_F, depth of cranial endocast at level of hypophyseal fossa; HF_NII, distance from hypophyseal fossa to n.II; NAS_CAP_L, length of nasal capsules; NII_OLF_BIF, distance from $n$.II to point of bifurcation between olfactory canals; NV_HF, distance from n.V to hypophyseal fossa; NX_NV, distance from n.V to n.X; OLF_CAN_L, length of olfactory canals from nasal capsules to point of bifurcation; SAC_H, height of sacculus; SAC_L, length of sacculus; SCC_H, height of semicircular canals; SCC_L, length of semicircular canals from anterior to posterior; SCC_W, width of semicircular canals from midline to lateral canal; UTR_H, height of utriculus; UTR_L, length of utriculus.

Figure 3. Principle Component Analysis for incomplete data (InDaPCA) biplot of lungfish endocast shape between A, PCA 1 and PCA 2; B, PCA 1 and PCA 3; C, PCA 1 and PCA 4; D, PCA 2 and PCA 3; E, PCA 2 and PCA 4; F, PCA 3 and PCA 4. Explanation of variable abbreviations as per Figure 2. Loadings and eigenvalues shown in Supplementary Figure 9.

\section{SUPPLEMENTARY FIGURES}

SI-Figure 1. Endocast of Griphognathus whitei (NHMUK PV P56054) in a, dorsal; b, lateral; c, ventral views. SI-Figure 2. Endocast of lowadipterus halli (FMNH PF 12323) in a, dorsal; b, lateral left; c, lateral right; and d, ventral views.

SI-Figure 3. Endocast of Orlovichthys limnatis (PIN 3725/110) in a, dorsal; b, lateral left; c, lateral right; and d, ventral views.

SI-Figure 4. Endocast of Pillararhynchus longi (ANU 49196) in a, dorsal; b, lateral left; c, lateral right; and d, ventral views.

SI-Figure 5. Endocast of Gogodipterus paddyensis (WAM 70.4.250) labyrinth region in a, dorsal; and b, right lateral views with transparent skull overlay; $\mathbf{c}$, dorsal; $\mathbf{d}$, right lateral; $\mathbf{e}$, anterior; $\mathbf{f}$, posterior views of labyrinth endocast only.

SI-Figure 6. Endocast of Rhinodipterus ulrichi (NRM P6609a) in a, dorsal; b, lateral left; c, lateral right; and d, ventral views.

SI-Figure 7. Standard Principle Component Analysis (PCA) without missing data, optimised for maximum number of CHARACTERS (13 characters, 7 taxa). A, optimal character PCA plot; and B, loadings for PC1-4; and C, distribution of eigenvalues.

SI-Figure 8. Standard Principle Component Analysis (PCA) without missing data, optimised for maximum number of TAXA (9 characters, 9 taxa). A, optimal taxa PCA plot; and B, loadings for PC1-4; and C, distribution of eigenvalues.

SI-Figure 9. Principle Component Analysis for incomplete data (InDaPCA) A, loadings for PC1-4; and B, distribution of eigenvalues of the InDaPCA. 
760

\section{OTHER SUPPLEMENTARY MATERIAL}

Table 1. Sheet 1, Comments and variables; Sheet 2, Endocast matrix; Sheet 3, PCA optimised for max. characters loadings; Sheet 4, PCA optimised for max. taxa loadings; Sheet 5, BPCA loadings; and Sheet 6 , InDaPCA loadings.

\section{DATA AVAILABLILITY}

All data generated or analysed during this study are included in the manuscript, supporting files (9 figures and 1 spreadsheet), or via a relevant online repository. Scan data from Chirodipterus wildungensis, Gogodipterus paddyensis, lowadipterus halli, Pillararhynchus longi and Rhinodipterus ulrichi can be found on MorphoSource at: https://www.morphosource.org/projects/000381944?locale=en, Griphognathus whitei and Orlovichthys limnatis have been deposited on Dryad: https://doi.org/10.5061/dryad.2rbnzs7p8 .

\section{REFERENCES}

Ahlberg PE. 1991. A re-examination of sarcopterygian interrelationships, with special reference to Porolepiformes. Zoological Journal of the Linnean Society 103:241-287.

Barwick RE, and Campbell KSW. 1996. A Late Devonian dipnoan, Pillararhynchus, from Gogo, Western Australia, and its relationships. Paleontographica Abt A 239:1-42.

Boirot M, Challands T, and Cloutier R. in press. Paedomorphic trait related to neurocranial ossification in two Devonian lungfishes (Givetian Pentlandia macroptera and Frasnian Scaumenacia curta). Acta Palaeontologica Polonica.

Bruner E, Ogihara N, and Tanabe HC. 2018. Digital Endocasts: From Skulls to Brains. Japan: Springer.

Campbell KSW, and Barwick RE. 1982. The neurocranium of the primitive dipnoan Dipnorhynchus sussmilchi (Etheridge). Journal of Vertebrate Paleontology 2:286-327.

Campbell KSW, and Barwick RE. 1986. Palaeozoic lungfishes - a review. Journal of Morphology Supplement 1:9-131.

Campbell KSW, and Barwick RE. 2000. The braincase, mandible and dental structures of the Early Devonian lungfish Dipnorhynchus kurikae from Wee Jasper, New South Wales. Records of the Australian Museum 52:103-128.

Challands TJ. 2015. The cranial endocast of the Middle Devonian dipnoan Dipterus valenciennesi and a fossilised dipnoan otoconal mass. Papers in Palaeontology 1:289-317.

Challands TJ, Pardo JD, and Clement AM. 2020. Mandibular musculature constrains brain-endocast disparity between sarcopterygians. Royal Society Open Science 7:1-20.

Challands TJ, Smithson TR, Clack JA, Bennett CE, Marshall JEA, Wallace-Johnson SM, and Hill H. 2019. A lungfish survivor of the end-Devonian extinction and an Early Carboniferous dipnoan radiation. Journal of Systematic Palaeontology:1-22. http://dx.doi.org/10.1080/14772019.2019.1572234 Clement AM. 2012. A new species of long-snouted lungfish from the Late Devonian of Australia, and its functional and biogeographical implications. Palaeontology 55:51-71.

Clement AM, and Ahlberg PE. 2014. The first virtual cranial endocast of a lungfish (Sarcopterygii: Dipnoi). PloS One 9:e113898. 10.1371/journal.pone.0113898

Clement AM, Challands TJ, Long JA, and Ahlberg PE. 2016a. The cranial endocast of Dipnorhynchus sussmilchi (Sarcopterygii: Dipnoi) and the interrelationships of stem-group lungfishes. PeerJ 4:e2539. 10.7717/peerj.2539

Clement AM, King B, Giles S, Choo B, Ahlberg PE, Young GC, and Long JA. 2018. Neurocranial anatomy of an enigmatic Early Devonian fish sheds light on early osteichthyan evolution. eLife 7:e34349. DOI: https://doi.org/10.7554/eLife.34349 
bioRxiv preprint doi: https://doi.org/10.1101/2021.09.13.460037; this version posted September 15, 2021. The copyright holder for this preprint (which was not certified by peer review) is the author/funder, who has granted bioRxiv a license to display the preprint in perpetuity. It is made available under aCC-BY 4.0 International license.

Clement AM, Nysjö J, Strand R, and Ahlberg PE. 2015. Brain - endocast relationship in the Australian lungfish, Neoceratodus forsteri, elucidated from tomographic data (Sarcopterygii: Dipnoi). PloS One 10:e0141277. DOI: 10.1371/journal.pone.0141277

Clement AM, Strand R, Nysjö J, Long JA, and Ahlberg PE. 2016b. A New Method for Reconstructing Brain Morphology: Applying The Brain-Neurocranial Spatial Relationship In An Extant Lungfish To A Fossil Endocast. Royal Society Open Science 3:160307. http://dx.doi.org/10.1098/rsos.160307

Cloutier R. 1997. Morphologie et variations du toit crânien du Dipneuste Scaumenacia curta (Whiteaves) (Sarcopterygii), du Dévonien supérieur du Québec. Geodiversitas 19:61-105.

Criswell KE. 2015. The comparative osteology and phylogenetic relationships of African and South American lungfishes (Sarcopterygii: Dipnoi). Zoological Journal of the Linnean Society. doi: 10.1111/zoj.12255 Dutel H, Galland M, Tafforeau P, Long JA, Fagan MJ, Janvier P, Herrel A, Santin MD, Clement G, and Herbin M. 2019. Neurocranial development of the coelacanth and the evolution of the sarcopterygian head. Nature 569:556-559. https://doi.org/10.1038/s41586-019-1117-3

Edinger T. 1921. Über Nothosaurus, Ein Steinkern der Schädelhöhle. Senckenbergiana 3:121-129.

Forster-Cooper C. 1937. The Middle Devonian fish fauna of Achanarras. Transactions of the Royal Society of Edinburgh 59:223-239.

Friedman M. 2007. The interrelationships of Devonian lungfishes (Sarcopterygii: Dipnoi) as inferred from neurocranial evidence and new data from the genus Soederberghia Lehman, 1959. Zoological Journal of the Linnean Society 151:115-171.

Gess RW, and Clement AM. 2019. A high latitude Devonian lungfish, from the Famennian of South Africa. PeerJ 7:e8073. DOI 10.7717/peerj.8073

Gross W. 1933. Die Agnathen und Fische des rheinischen Devons. Abhandlungen der Preussischen Geologischen Landesanstalt 154:1-83.

Henderson SAC, and Challands TJ. 2018. The cranial endocast of the Upper Devonian dipnoan 'Chirodipterus' australis. PeerJ 6:e5148. DOI 10.7717/peerj.5148

Jerison HJ. 1973. Evolution of the Brain and Intelligence. United States of America: Academic Press, Inc.

Kemp A. 2000. Chirodipterus potteri, a new Devonian lungfish from New South Wales, Australia: and the ontogeny of chirodipterid tooth plates. Journal of Vertebrate Paleontology 20:665-674.

Kemp AD, and Kirk EC. 2014. Eye size and visual acuity influence vestibular anatomy in mammals. The Anatomical Record 297:781-790.

Ladich F, and Schulz-Mirbach T. 2016. Diversity in Fish Auditory Systems: One of the Riddles of Sensory Biology. Frontiers in Ecology and Evolution 4:1-26. doi: 10.3389/fevo.2016.00028

Lauridsen H, Hansen K, Wang T, Agger P, Andersen JL, Knudsen PS, Rasmussen AS, Uhrenholt L, and Pedersen M. 2011. Inside out: Modern imaging techniques to reveal animal antomy. PloS One 6:e17879. doi:10.1371/journal.pone.0017879

Long JA. 1992b. Gogodipterus paddyensis gen. nov., a new chirodipterid lungfish from the Late Devonian Gogo Formation, Western Australia. The Beagle, NT Museum 9.

Malinzak MD, Kay RF, and Hullar TE. 2012. Locomotor head movements and semicircular canal morphology in primates. Proceedings of the National Academy of Sciences 109:17914-17919.

Marshall CR. 1986. Lungfish: Phylogeny and Parsimony. Journal of Morphology Supplement 1:151-162.

Miles RS. 1977. Dipnoan (lungfish) skulls and the relationships of the group: a study based on new species from the Devonian of Australia. Zoological Journal of the Linnean Society 61:1-328.

Mörs T. 1991. An unusual large lungfish tooth plates (Dipnoi, Chirodipteridae) from the Middle Devonian of the Rhenish Massif (Bergisches Land, Germany). Neues Jahrbuch Geologie und Paläontologie, Monatshefte 11:654-662.

Nieuwenhuys R, Donkelaar HJ, and Nicholson C. 1998. The Central Nervous System of Vertebrates: Springer Berlin Heidelberg.

Northcutt RG. 1986. Lungfish neural characters and their bearing on sarcopterygian phylogeny. Journal of Morphology Supplement 1:277-297.

Northcutt RG. 2011. The Central Nervous System of Lungfishes. In: Jørgensen JM, and Joss J, eds. The Biology of Lungfishes. Enfield, USA: Science Publishers, 393-445. 
Oba S, Sato MA, Takemasa I, Monden M, Matsubara KI, and Ishii S. 2003. A Bayesian missing value estimation method for gene expression profile data. Bioinformatics 19:2088-2096.

Platt C, Jørgensen JM, and Popper AN. 2004. The inner ear of the lungfish Protopterus. The Journal of Comparative Neurology 471:277-288.

Podani J, Kalapos T, Barta B, and Schmera D. 2021. Principal component analysis of incomplete data-A simple solution to an old problem. Ecological Informatics 61:p.101235.

Qiao T, and Zhu M. 2009. A new tooth-plated lungfish from the Middle Devonian of Yunnan, China, and its phylogenetic relationships. Acta Zoologica 90:236-252.

Ramcharitar JU, Deng X, Ketten DR, and Popper AN. 2004. Form and function in the unique inner ear of a teleost: The silver perch (Bairdiella chrysoura). Journal of Comparative Neurology 475:531-539.

Säve-Söderbergh G. 1952. On the skull of Chirodipterus wildungensis Gross, an Upper Devonian dipnoan from Wildungen. Kunglinga Svenska Vetenskapsakademiens Handlingar 4 3:1-29.

Schultze H-P. 1982. A dipterid dipnoan from the Middle Devonian of Michigan, U.S.A. Journal of Vertebrate Paleontology 2:155-162.

Schultze HP. 1986. Dipnoans as Sarcopterygians. Journal of Morphology Supplement 1:39-74.

Schultze HP. 1992. A new long-headed dipnoan (Osteichthyes) from the Middle Devonian of lowa, USA. Journal of Vertebrate Paleontology 12:42-58.

Sedgwick A, and Murchison RI. 1828. On the structure and relations of the deposits contained between the primary rocks and the oolitic series in the north of Scotland. Transactions of the Geological Society, London 2:125-160.

Sharp EL, and Clack JA. 2013. A review of the Carboniferous lungfish genus Ctenodus Agassiz, 1838 from the United Kingdom, with new data from an articulated specimen of Ctenodus interruptus Barkas, 1869. Earth and Environmental Science Transactions of the Royal Society of Edinburgh 104:169-204.

Song CQ, and Chang MM. 1991. Discovery of Chirodipterus (Dipnoi) from lower Upper Devonian of Hunan, south China. In: Chang MM, Liu YH, and Zhang GR, eds. Early Vertebrates and Related Problems of Evolutionary Biology. Beijing: Science Press.

Spoor F, Bajpai S, Hussain ST, Kumar K, and Thewissen JGM. 2002. Vestibular evidence for the evolution of aquatic behaviour in early cetaceans. Nature 417:163-166.

Stacklies W, Redestig H, Scholz M, Walther D, and Selbig J. 2007. pcaMethods-a bioconductor package providing PCA methods for incomplete data. Bioinformatics 23:1164-1167.

Stensiö E. 1963. The Brain and the Cranial Nerves in Fossil, Lower Craniate Vertebrates. Skrifter utgitt av Det Norske Videnskaps-Akademi:1-120.

Striedter GF, and Northcutt RG. 2020. Brains Through Time: A Natural History of Vertebrates. New York: Oxford University Press.

Walsh SA, and Knoll MA. 2011. Directions in palaeoneurology. Palaeontology 86:263-279.

Wang S, Drapala V, Barwick RE, and Campbell KSW. 1993. The dipnoan species, Sorbitorhynchus deleaskitus, from the Lower Devonian of Guangxi, China. Philosophical Transactions of the Royal Society of London (Biol) 340:1-24.

Willis KL, Christensen-Dalsgaard J, Ketten DR, and Carr CE. 2013. Middle ear cavity morphology is consistent with an aquatic origin for testudines. PloS One 8:e54086. doi:10.1371/journal.pone.0054086

Yopak KE, Lisney TJ, and Collin SP. 2015. Not all sharks are "swimming noses": variation in olfactory bulb size in cartilaginous fishes. Brain Structure and Function 220:1127-1143.

Yopak KE, Lisney TJ, Darlington RB, Collin SP, Montgomery JC, and Finlay BL. 2010. A conserved pattern of brain scaling from sharks to primates. PNAS 107:12946-12951.

Yopak KE, McMeans BC, Mull CG, Feindel KW, Kovacs KM, Lydersen C, Fisk AT, and Collin SP. 2019. Comparative brain morphology of the Greenland and Pacific sleeper sharks and its functional implications. Scientific Reports 9:1-15.

Zhu Y-A, Giles S, Young GC, Hu Y-Z, Bazzi M, Ahlberg PE, Zhu M, and Lu J. 2021. Endocast and Bony Labyrinth of a Devonian "Placoderm" Challenges Stem Gnathostome Phylogeny. Current Biology:1-7. https://doi.org/10.1016/i.cub.2020.12.046 


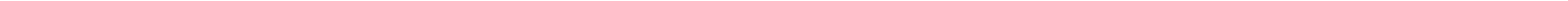



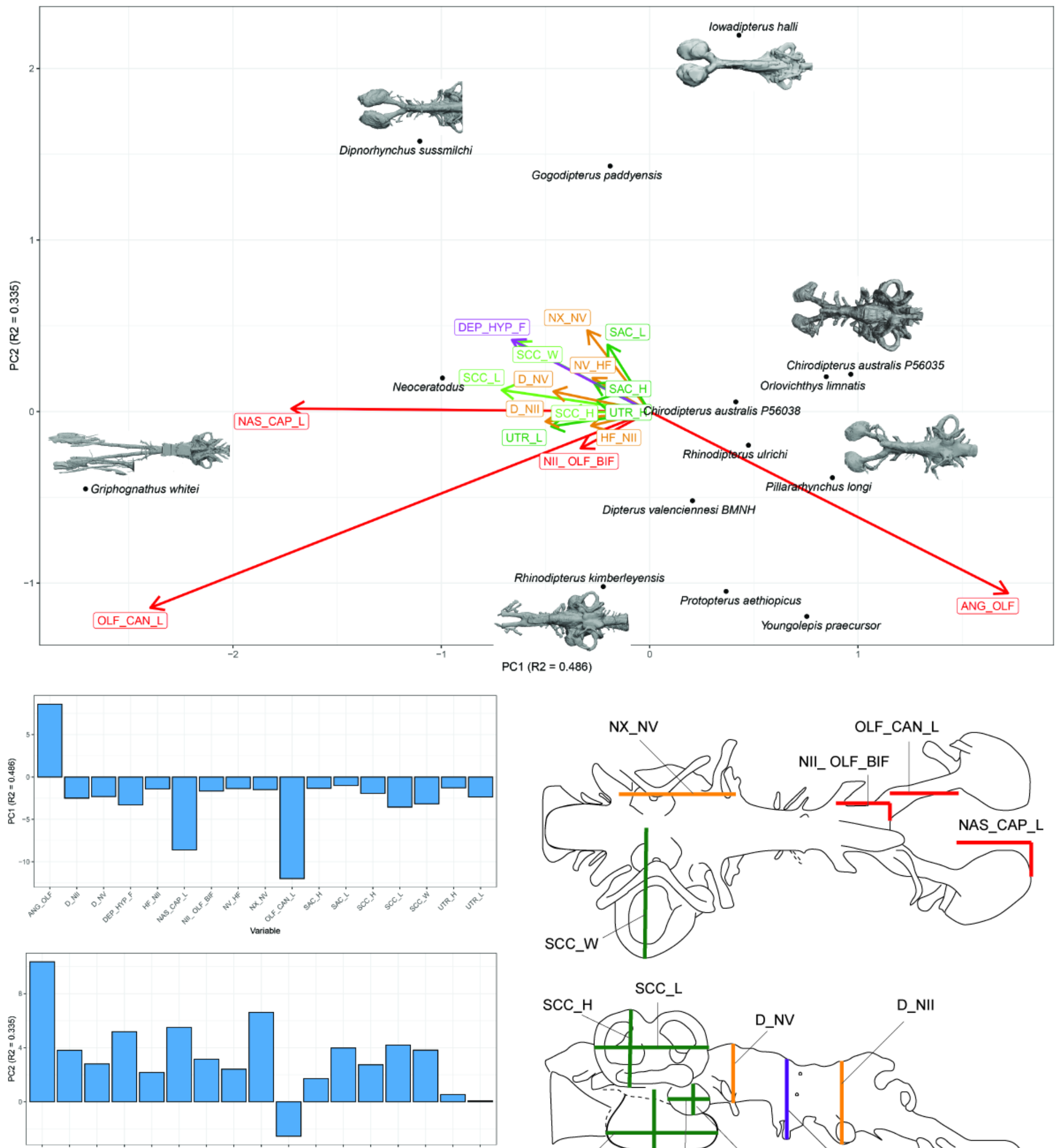

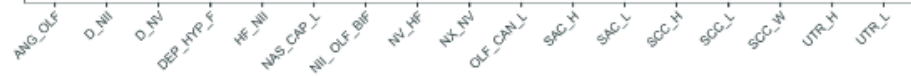
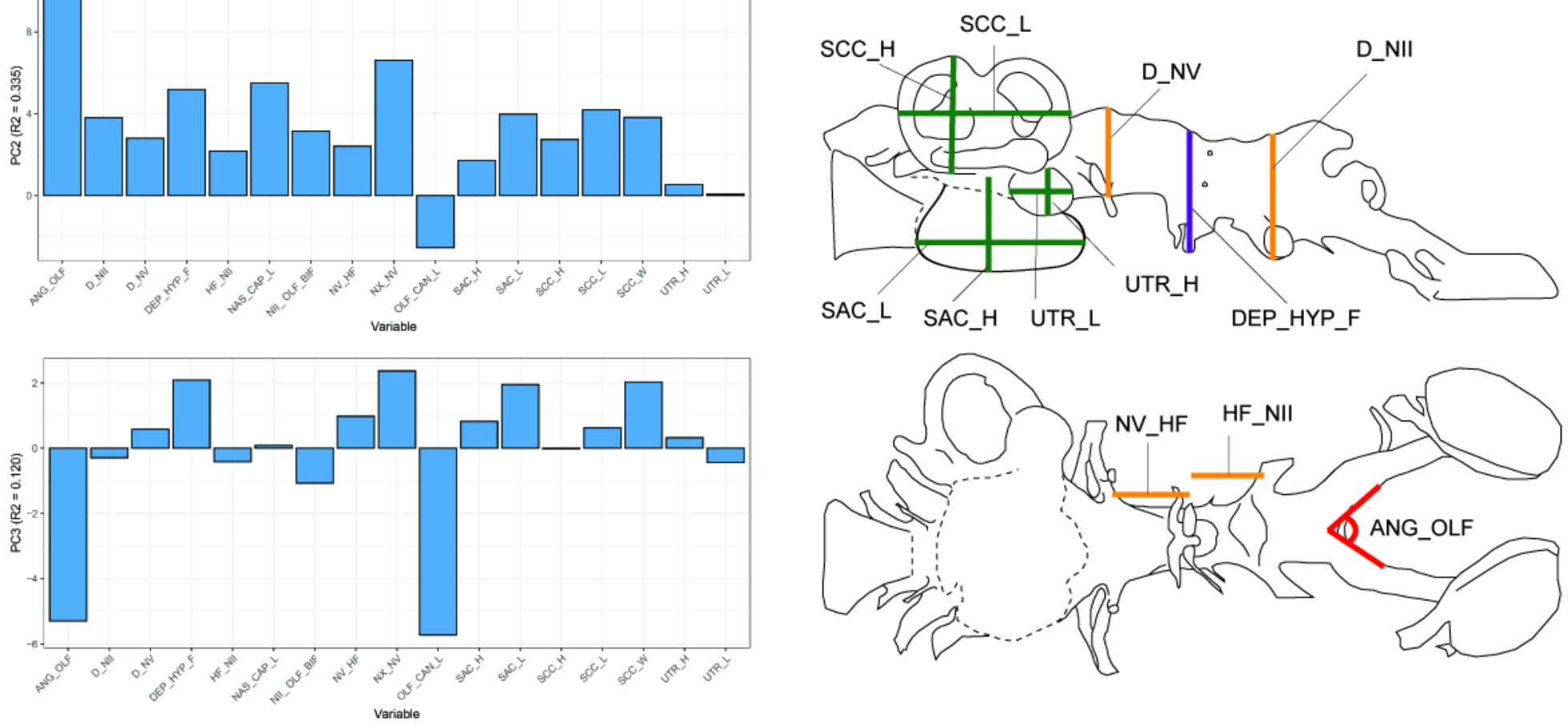

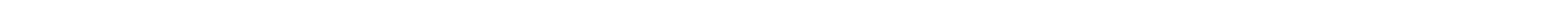


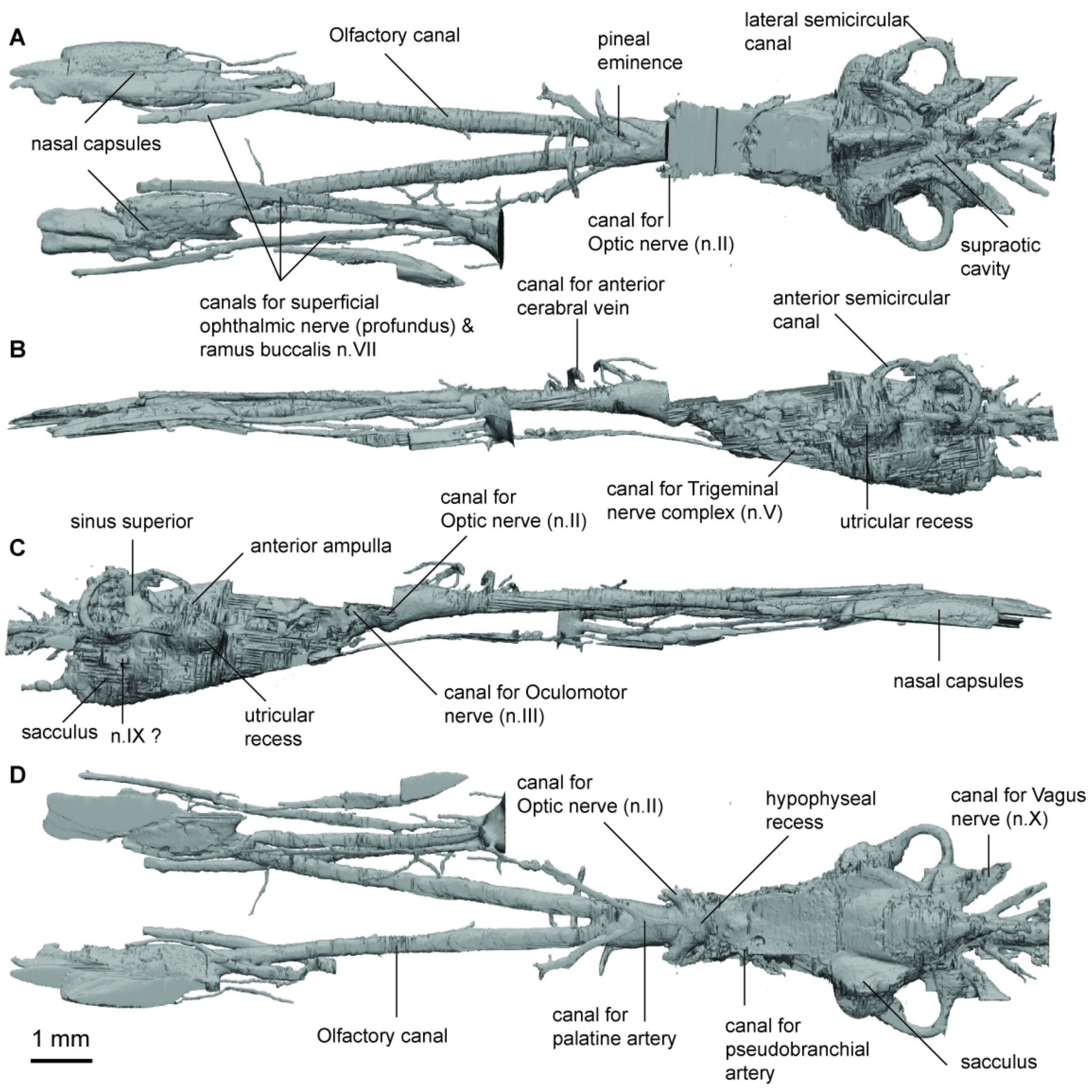


A
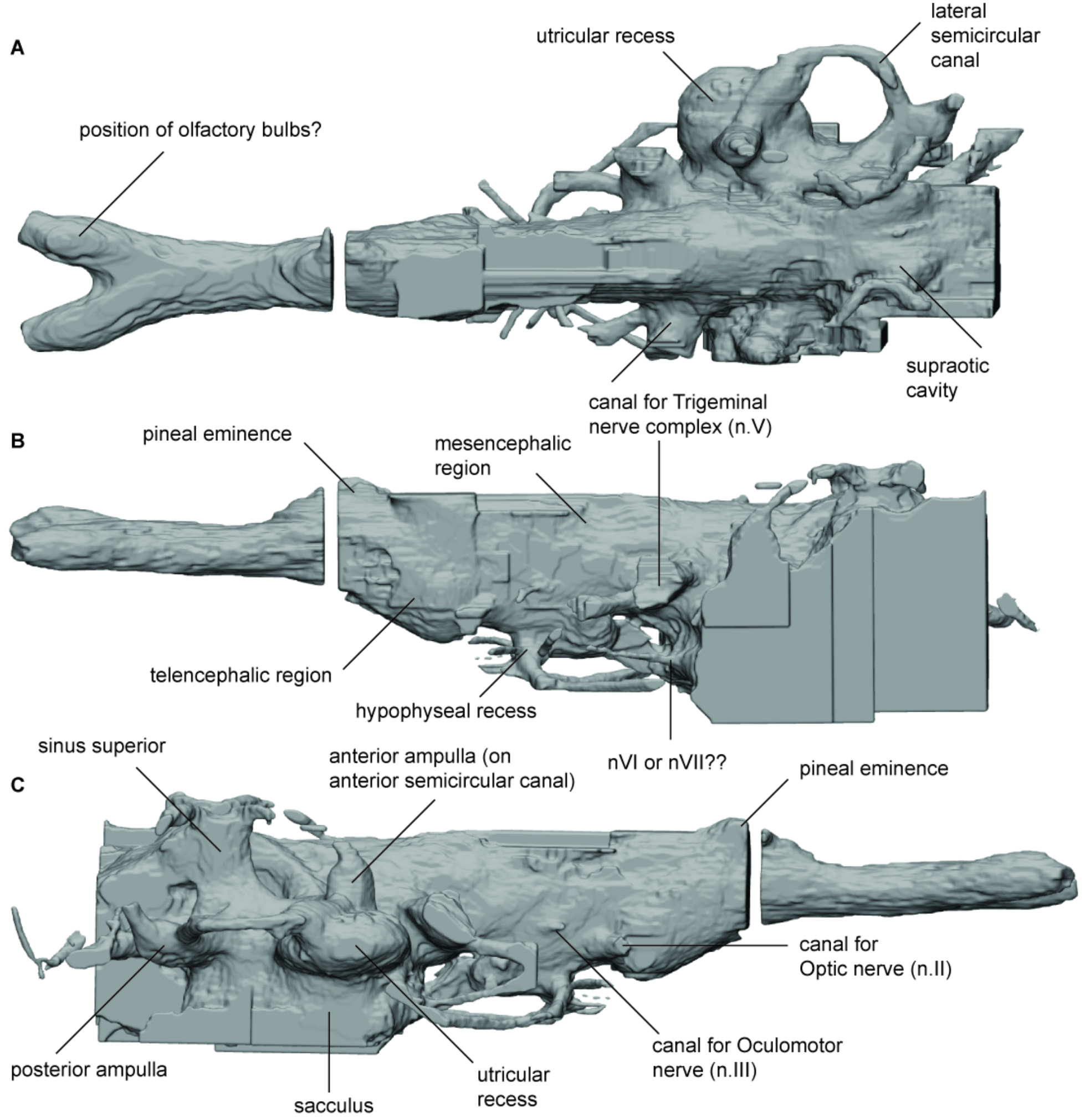

D

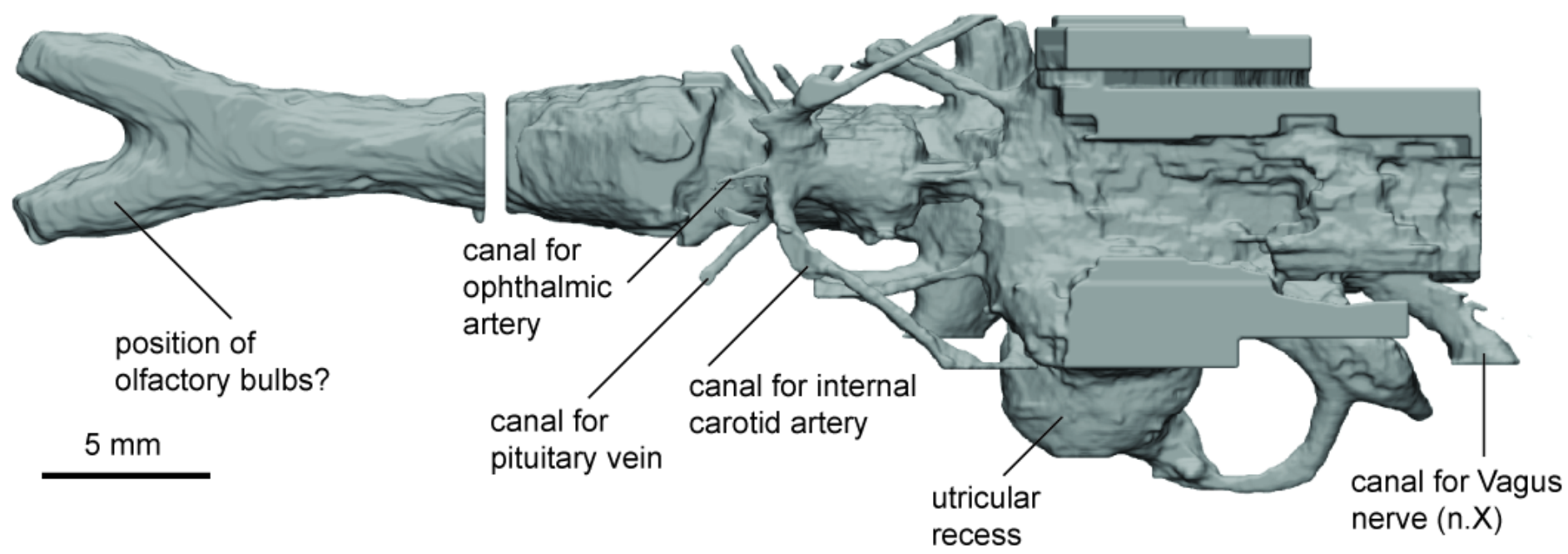




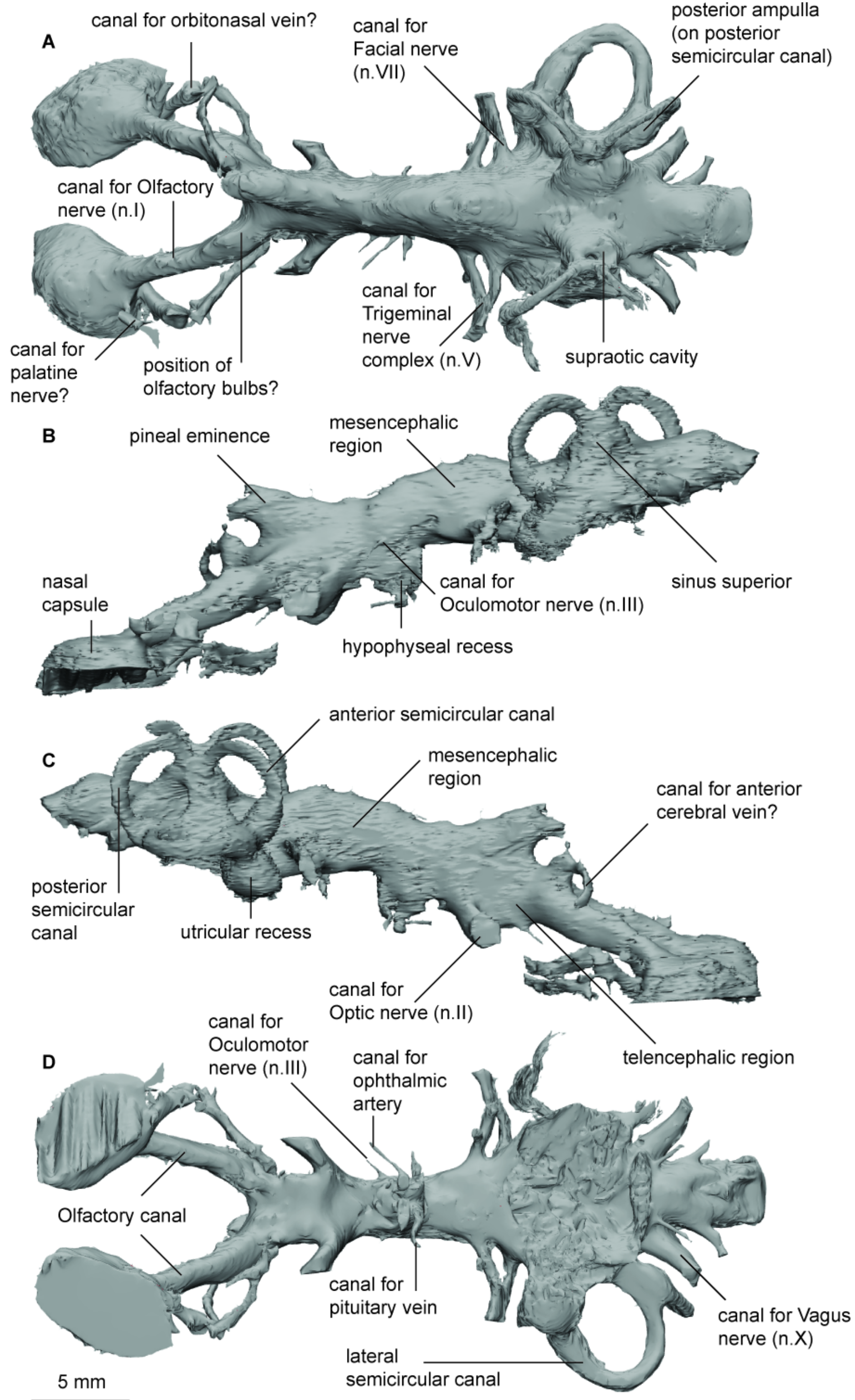


A
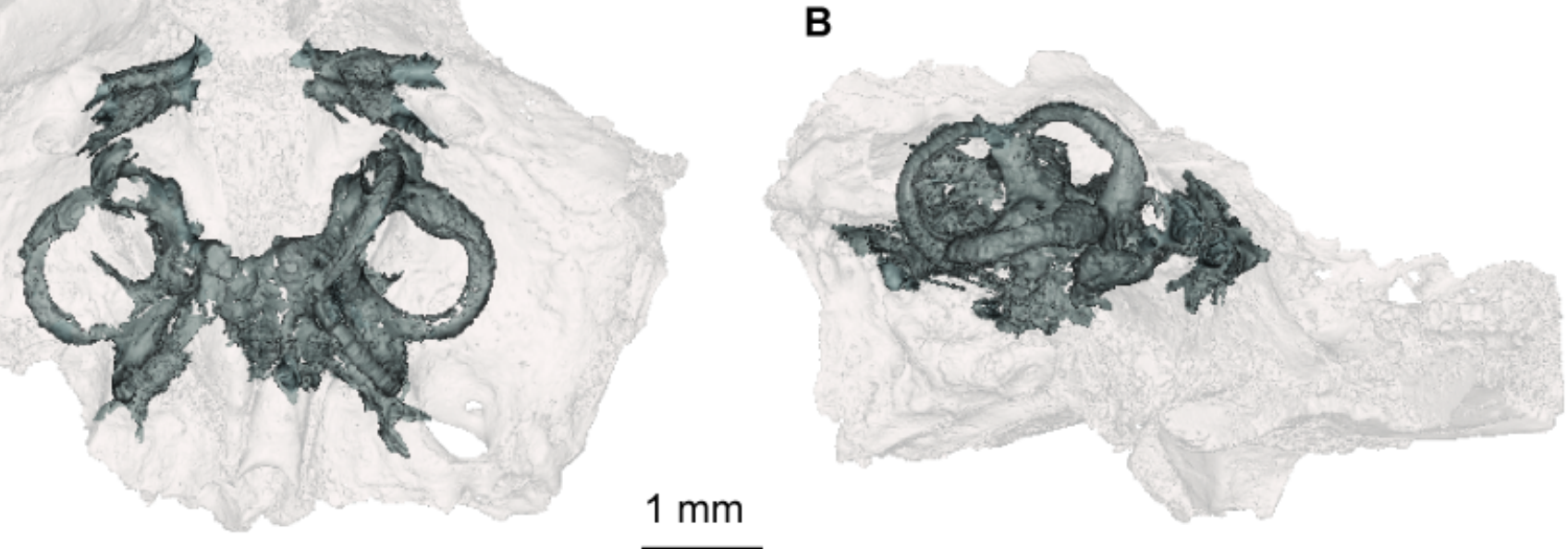

canal for Trigeminal

nerve complex (n.V)

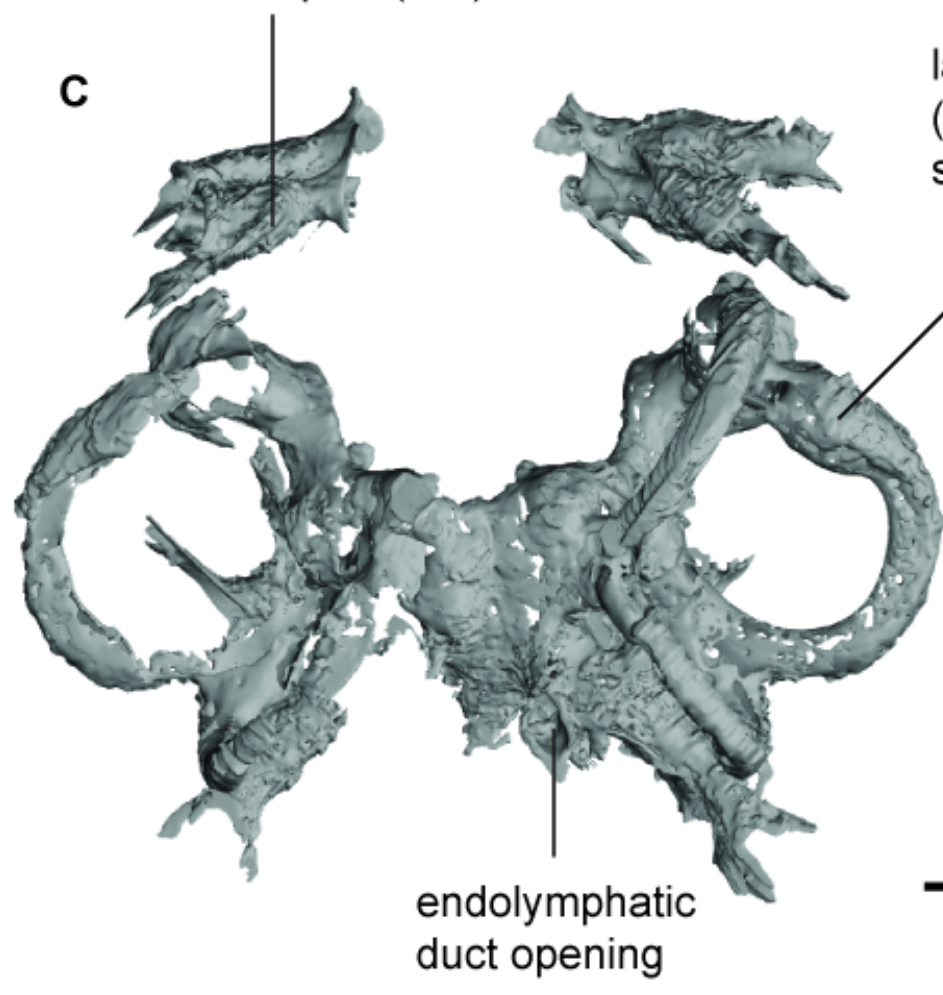

lateral ampulla

(on lateral

semicircular canal)

sinus superior anterior ampulla

\begin{tabular}{l|l} 
(on anterior
\end{tabular}

semicircular canal)

E

anterior semicircular canal

canal for Vagus

nerve (n.X)

$1 \mathrm{~mm}$

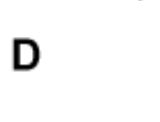



A
supraotic cavity

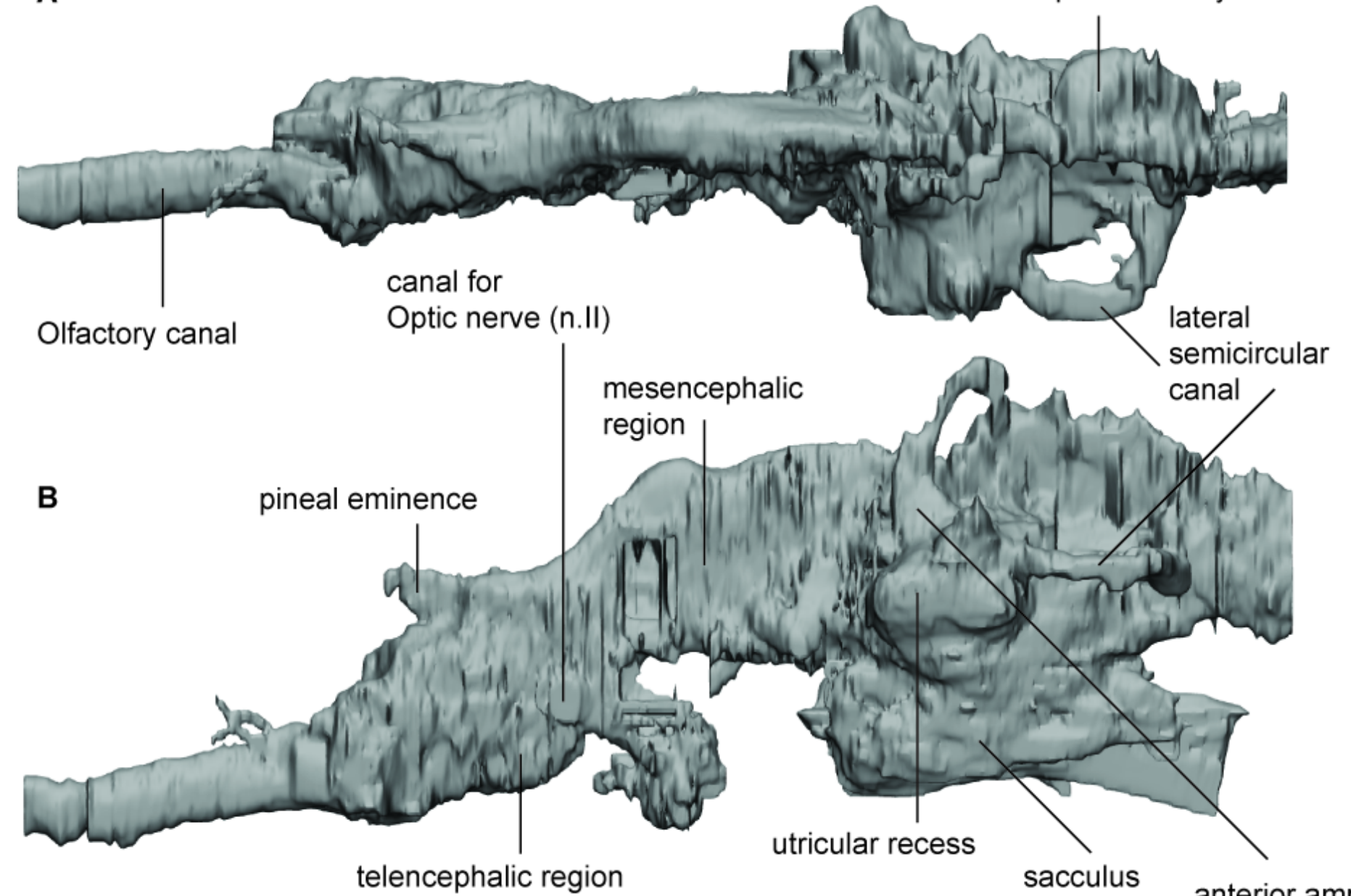

anterior ampulla (on anterior
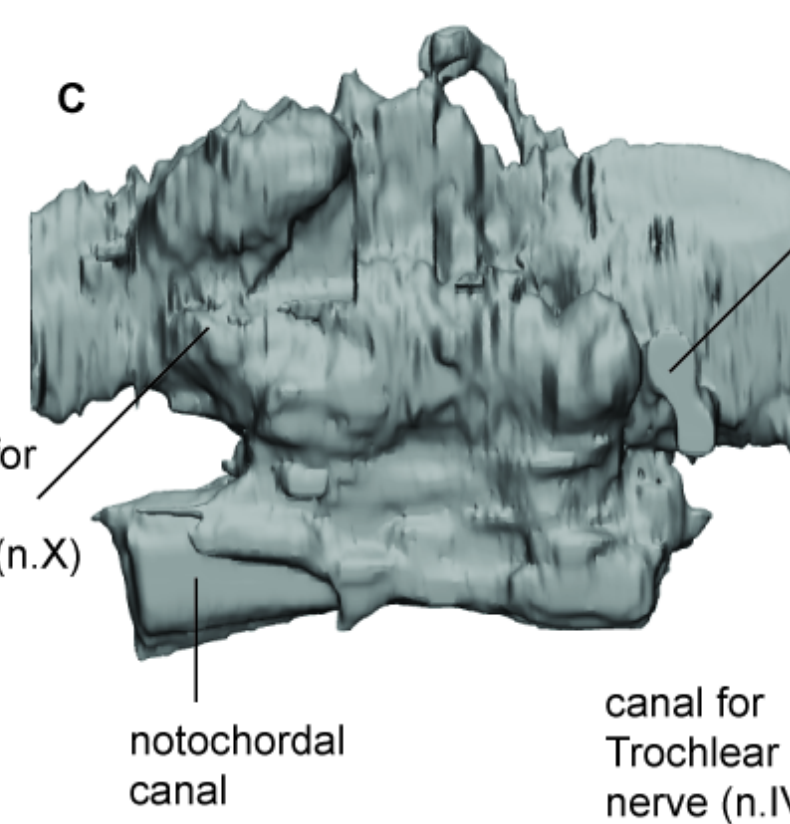

canal for Trigeminal

semicircular canal)

canal for Vagus nerve (n.X)

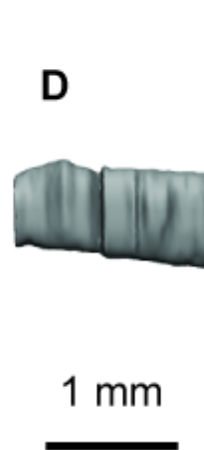

Trochlear nerve (n.IV)

nerve complex (n.V)

canal for Oculomotor

nerve (n.III) 

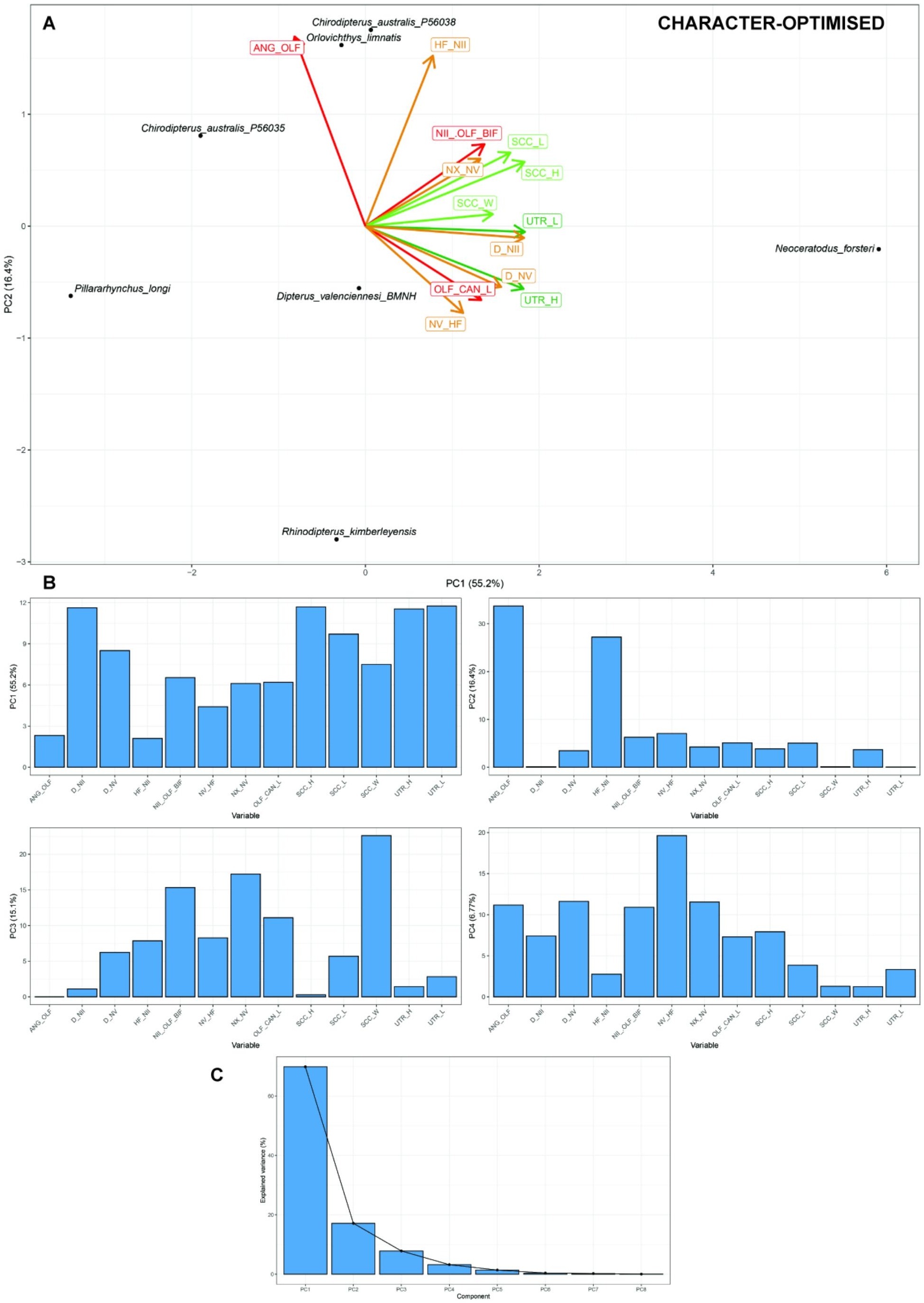


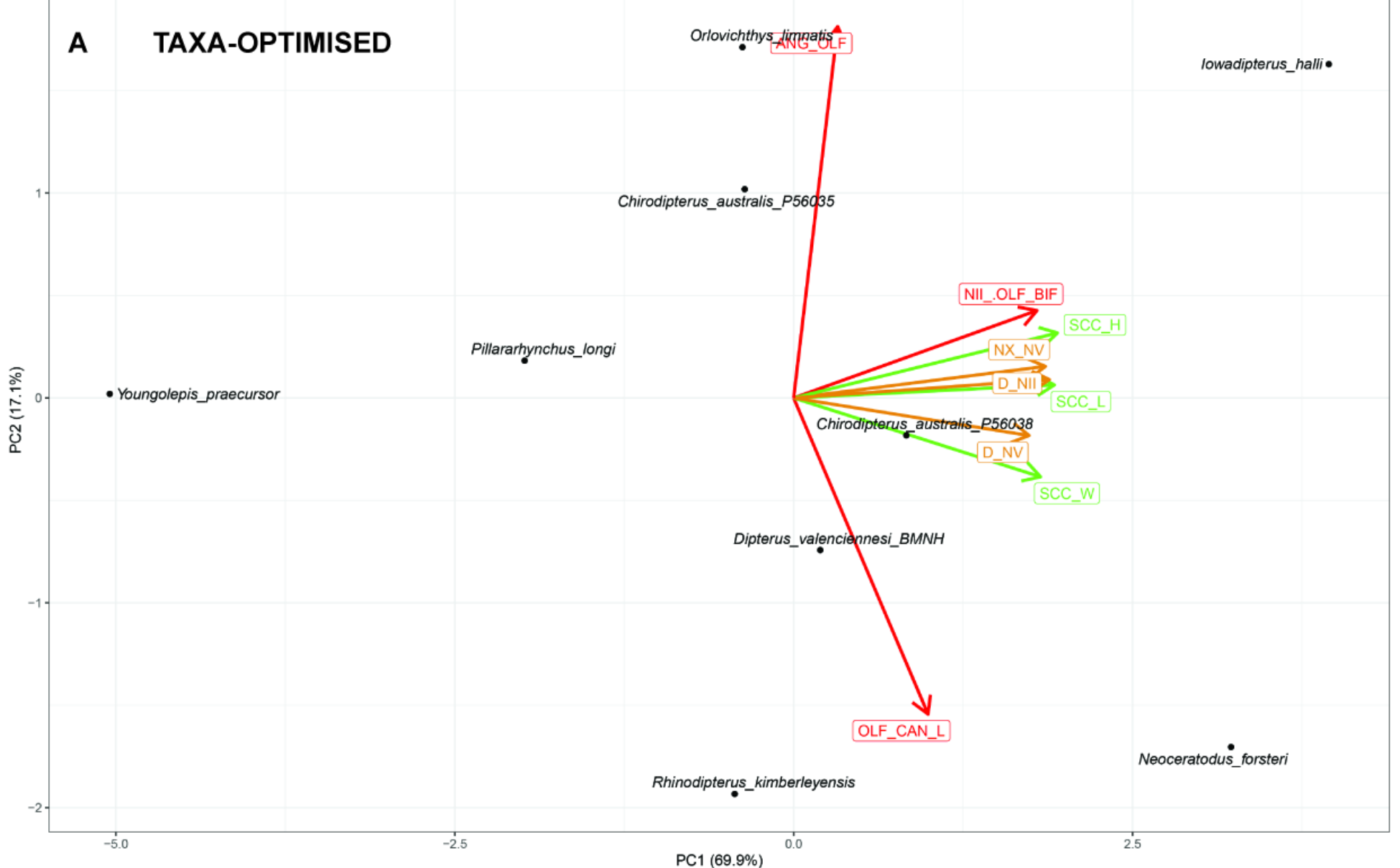

B
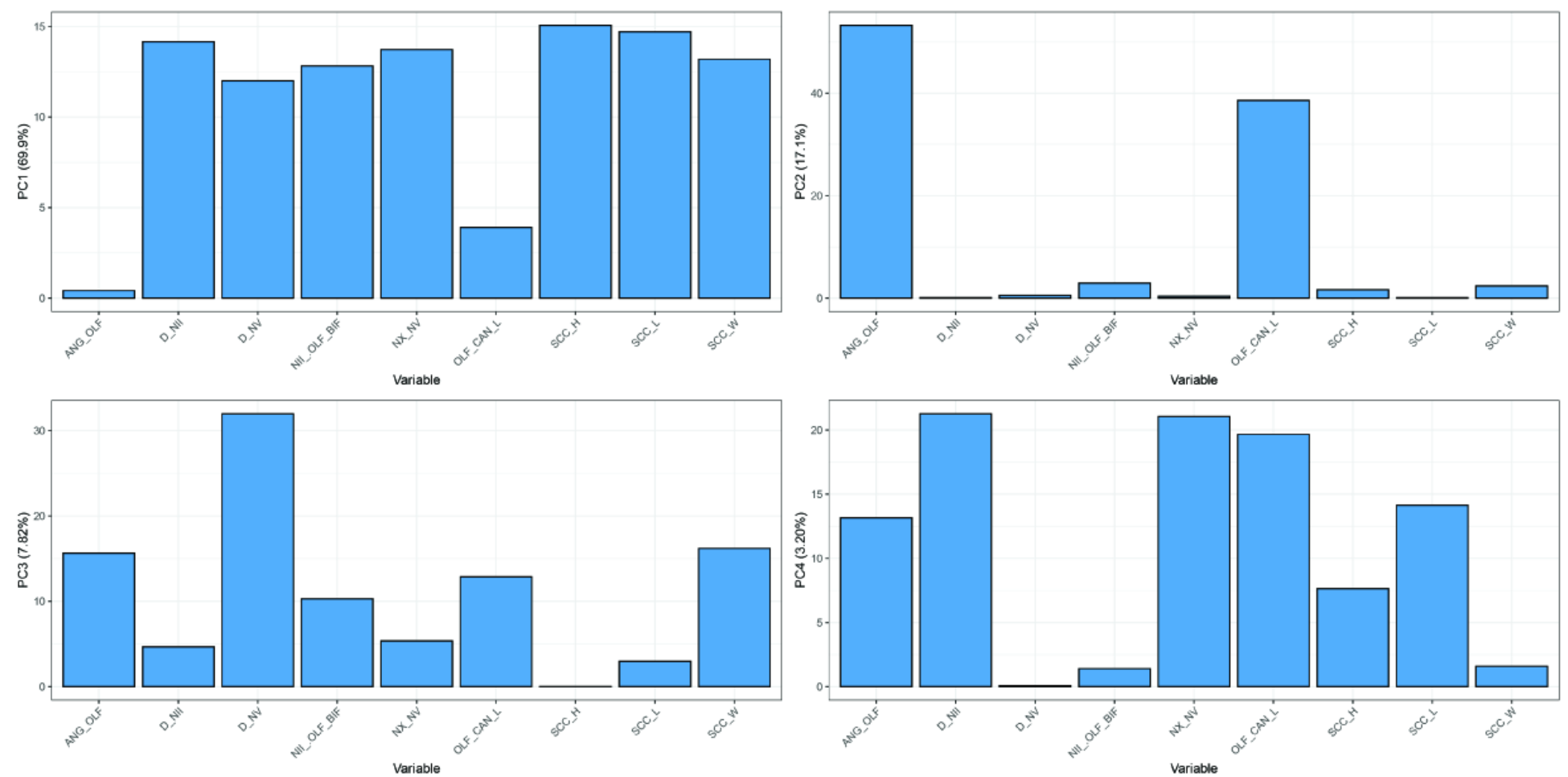

C

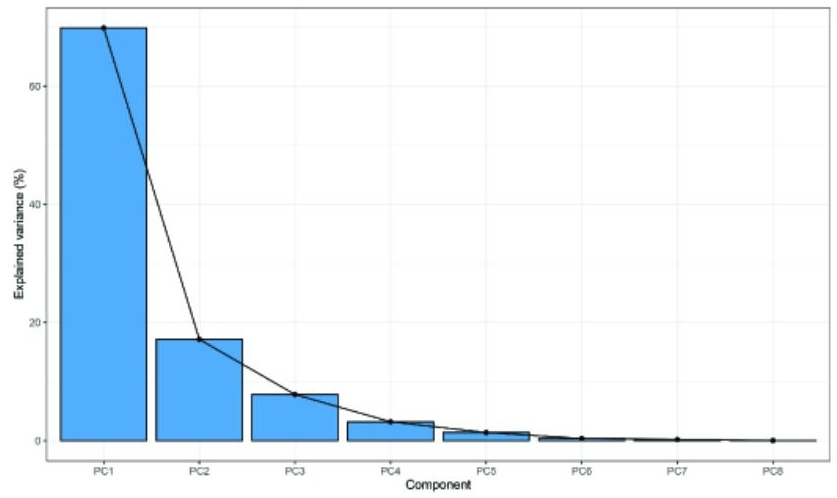



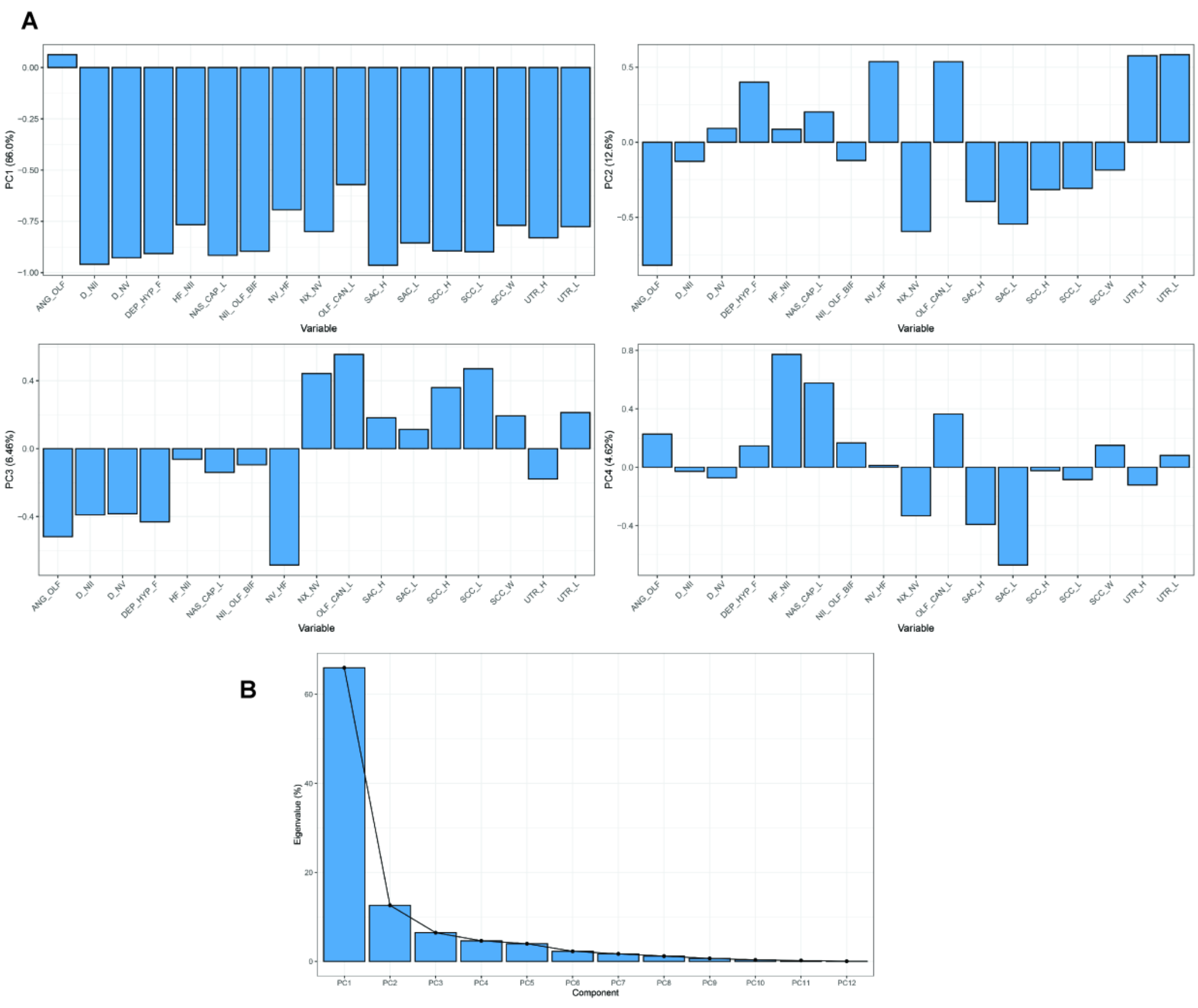